
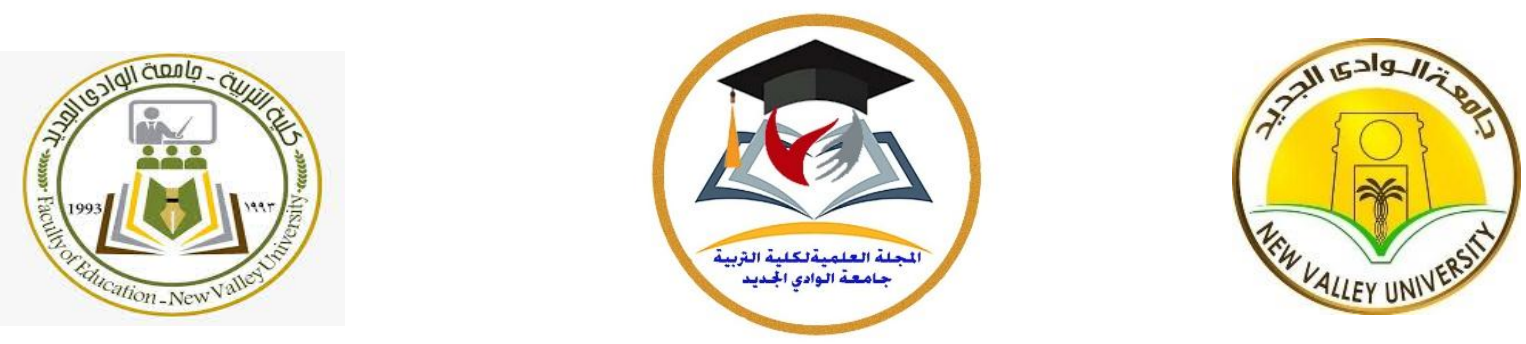

المخططات المعرفية اللاتكيفية وعلاقتها باضطراب الثََّّصية الاعتماديَّة لاى طلاب كلية التربية بالوادي الجديد

$$
\text { إسراء صداح مقدم من الباحثة }
$$

ضمن متطلبات الحصول على درجة الماجستير في التربية تخصص ( صحة نفسية)

$$
\text { إثراف }
$$

ا.م.د/ أسماء عثمان دياب عبد المقصود

استاذ الصحة النفسية المساعد

كلية التربية جامعة الوادي الجديد

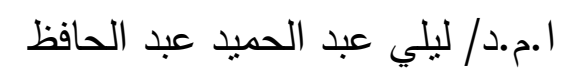

استاذ الصحة النفسية المساعد

كلية التربية جامعة الوادي الجديد

$$
\text { د/ سمية محمد مختار محمد }
$$

مدرس الصحة النفسية

كلية التربية جامعة الوادي الجديد

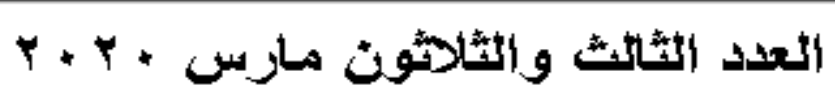

ISSN 2735-5209

\title{
E-mail: jedunewvallev@gmail.com
}


هدف البحث إلي تعرف الفروق بين النوع الاجتماعي في اضطراب الثخصية الاعتماديَّة، وتعرف العلاقة

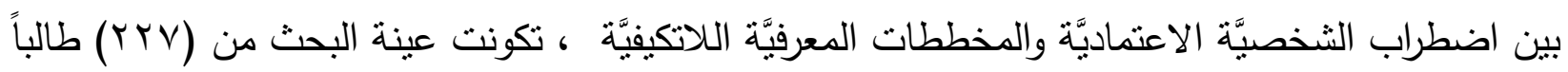
وطالبة من كلية التربية بالفرقة الثانية بمتوسط عمري قدره (9,1 (1) سنة ، وانحراف معياري قدره (0>, •) سنة، واشتملت أدوات البحث علي مقياس اضطراب الثخصية الاعتمادية إعداد الباحثة ، استبيان

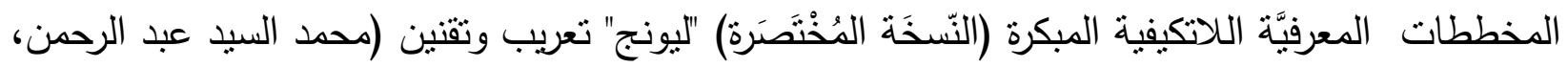

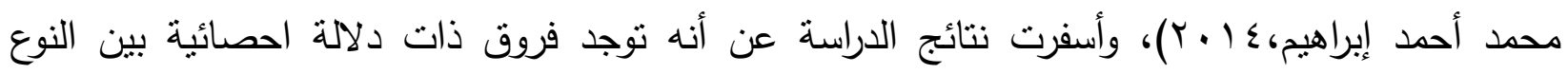
الاجتماعي في اضطراب الثخصية الاعتمادية لصالح الاناث، توجد علاقة ارتباطية موجبة دالة دانية احصائيا

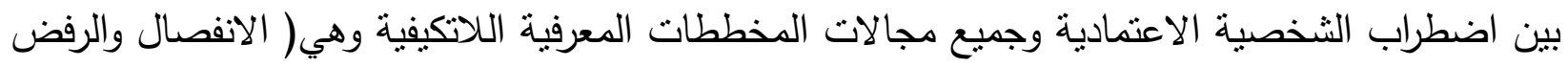

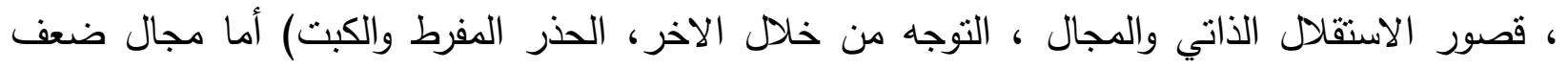
الحدود او القيود لا يرتبط بالاعتمادية. الكلمات المفتاحية/ المخططات المعرفية اللاتكيفية - اضطراب الثخصية الاعتمادية.

\section{Abstract}

This research aimed at knowing the differences between gender in dependent personality disorder , and to know its association with in dependent personality disorder and maladaptive schemas, The research sample consisted of (227) male and female students from the faculty of Education in the second year with an average age of (19.8) years, and a standard deviation of( 0.75$)$ years, The research tools included the Dependent Personality Disorder Scale prepared by the researcher, young's the Early maladaptive schemas Questionnaire (abbreviated version) arabization and Legalization (Muhammad al-Sayed AbdelRahman, Muhammad Ahmad Ibrahim, 2014), The results of the study revealed that there were statistically significant differences between gender in dependent personality disorder in favor of females, The existence of a positive statistically significant correlational relationship between dependent personality disorder and all areas of non-adaptive cognitive schemes, namely (separation and rejection, 
impaired autonomy and performance, other - directedness, over - vigilance while the field of impaired limits is not related to dependence.

Keywords: Maladaptive Schemas - dependent personality disorder. 
تصيب اضطرابات الثَّخصيَّة حوالي • (1: 10 \% من السُّكّان عموماً إلا أن المجموعة الثالثة من اضطرابات الثخصية كان لها النصيب الأكبر ويقع فيها اضطراب الثَّخصيَّة الاعتماديَّة

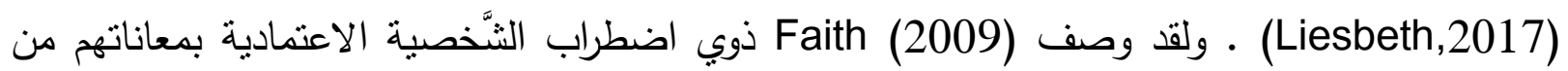
نقص شديد في الثّقة بالنَّس وصعوبة القيام بالمهام بدون مساندة الآخرين ورعايتهم وهذا سبب تكرار شعورهم

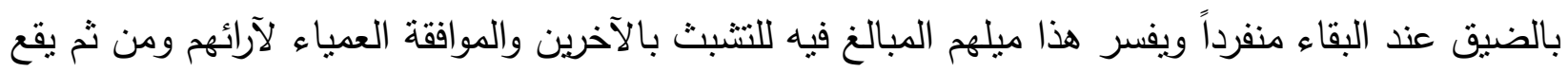

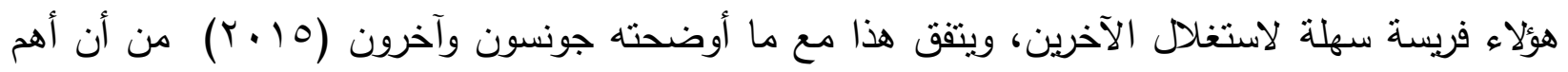

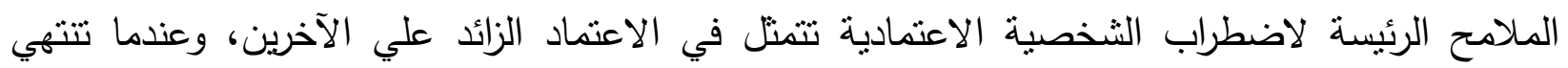
علاقة صداقة حميمة فإنَّهم يلحُّن في البحثِ عن علاقة أخرى بديلة لتحلَّ محل العلاقة المنتهية؛ فهم يرون أنفسهم ضعفاء ويلجأون إلي الآخرين للحصولِ علي المساندة واتخاذ القرار .

استخدم Young مصطلح المخططات اللاتكيفية المبكرة كمصطلح جوهري ورئيسي في دراسة علم الأمراض النفسية واضطرابات الثخصية وصعوبات العلاقات البينشخية في نظريته المعروفة "بنظرية المخططات "ليونج" Young's Schema Theory حيث افترض أن المخططات اللاتكيفية المبكرة تتكون جذورها عادة في مرحلة الطفولة التي تتَّم بالاضطراب أو إساءة المعاملة أو عدم تلبية الاحتياجات الأساسية للطفل، حيث كانت سببًا في ظهور الاضطرابات والمشكلات النَّفسية والثنَّنصية مسنقبلًا ( Theiler, ) 2005، حيث ترجع جذورها عادة إلي فترة طفولة (Young, Beck\& Weinberger, 1993). وتتكون

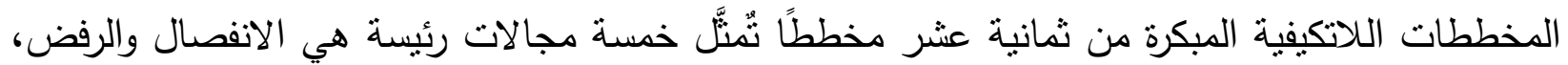
قصور الاستقلال الذاتي وضعف الأداء، عدم الالتزام بالحدود، التوجه من خلا الآخر، الحذر المفرط (Wang ,Halvorsen, Eisemann\& Waterloo, 2010)

مشكلة البحث وتساؤلاته

يُعد اضطراب الثَّصيّة الاعنماديّة من بين أكثر اضطرابات الثخصية انتشارًا في عيادات الصحّة

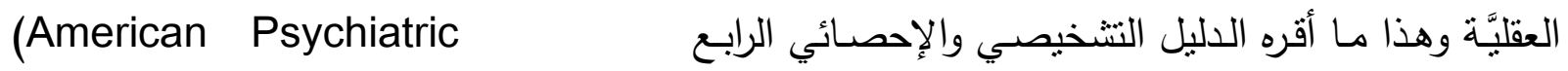

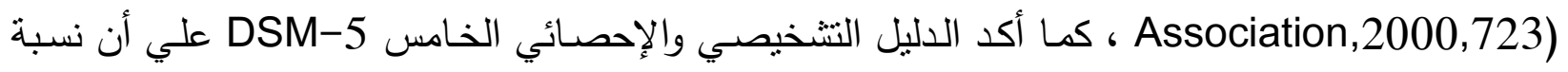

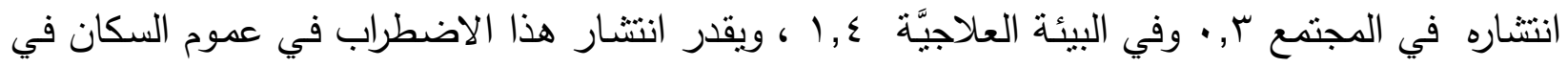
أقل من ا \% ،ويعاني منه النساء أكثر من الرجال (American Psychiatric Association,2013). 
يذكر (2021) Michal, Annamaria and Tillmann أن الثخص المصـاب باضطراب الثخصية الاعتمادية يواجه صعوبات كبيرة في اتخاذ أي قرارات بنفسه ويحتاج إلى شخص آخر قوي ليكون

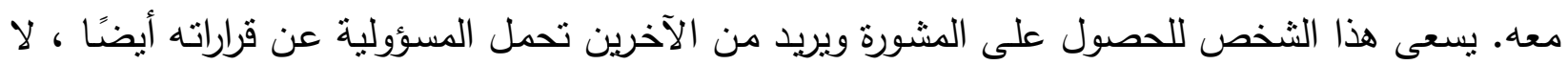
يسنطيع هؤلاء الأشخاص إظهار خلافهم مع الآخرين لأنهم يخشون الرفض وقد يقومون بمهام مزعجة للغاية الاحتية وغير مريحة لمجرد الحصول على الرعاية والدعم من الآخرين ويشعرون بضيق شديد عندما يكونون بمفردهم دون الآخرين وبسبب هذه الخصائص في العلاقات الثخصية يكونون مستعدين للمعاناة من سوء المعاملة لمجرد البقاء في علاقة وعندما تتتهي العلاقة فإنهم يحاولون بإلحاح العثور على شخص جديد يتشبثون به،

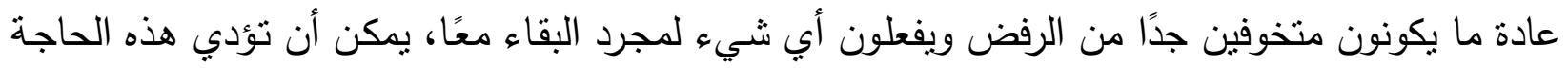

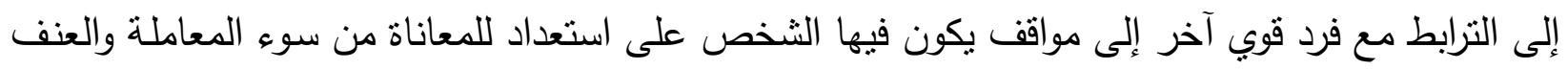
المنزلي ، فقط حتى لا يتم التخلي عنه. يؤدي اضطراب الثخصية الاعتمادية للعديد من الآثار السلبية ليس

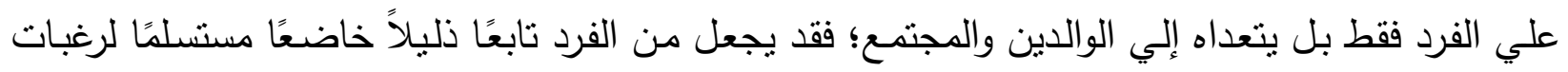

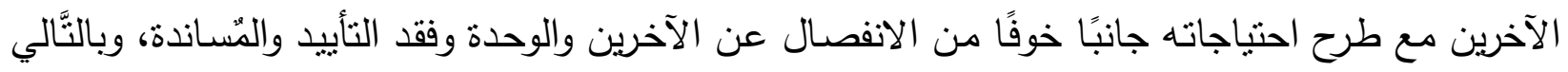

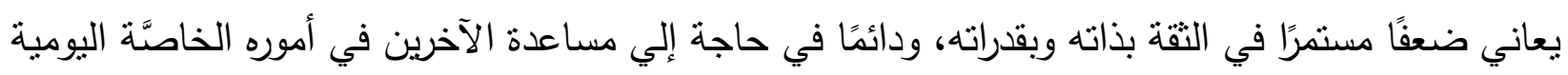

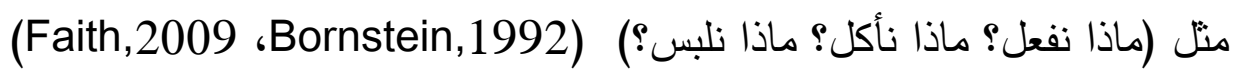

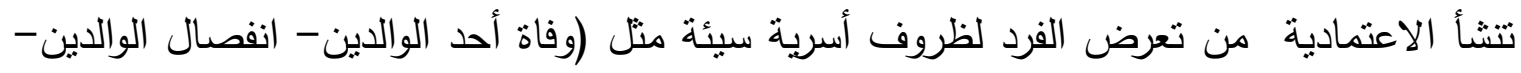

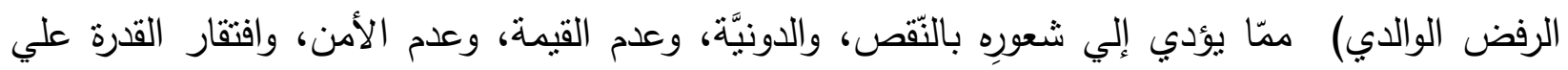

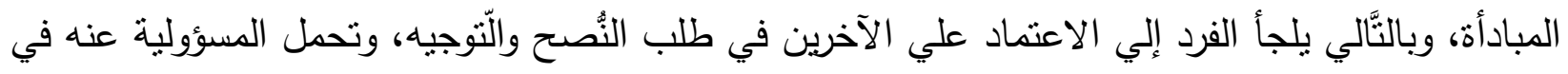

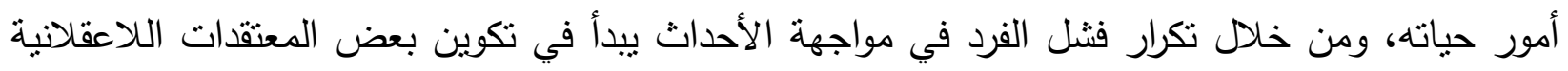

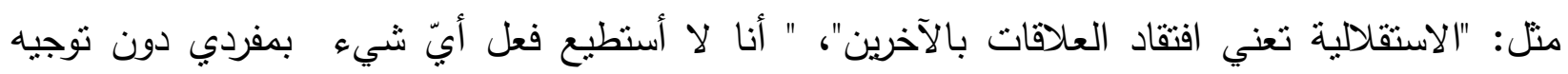

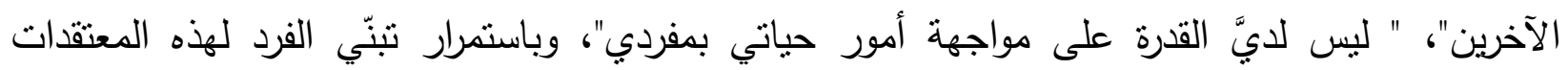

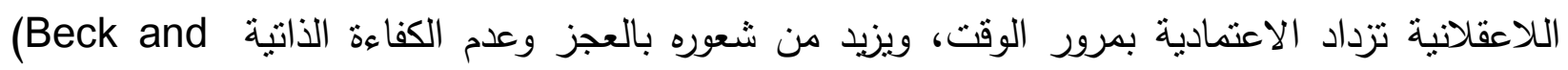

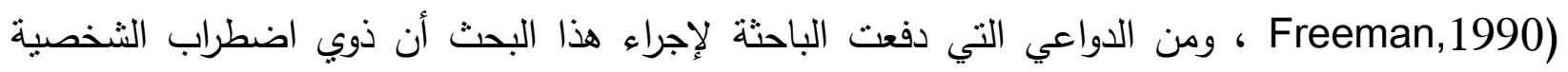

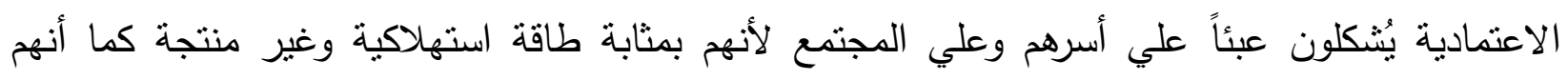
يحتاجون دائماً لمن يعولهم ويرعاهم. أثنتت بعض الدراسات وجود علاقة ارتباطيه بين المخططات المعرفية اللاتكيفَّة المبكرة وعديد من وني

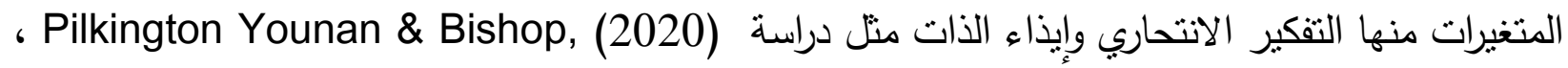
واضطراب الثخصيَّة الحدية منل دراسة هبة محمد علي( Hoda, David, Naysun\&، (ب)، 
Fritz, Jill, ، . IV V وأيضًا علاقتها بالأعراض الاكتئابية منت دراسة: (Michael, 2018 Frenk, Arnoud\& Marcus, 2012

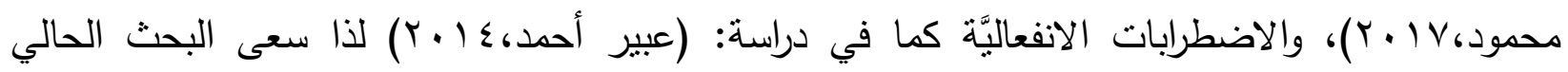
للكثف عن العلاقة الارتباطية بين اضطراب الثخصية الاعتمادية والمخططات المعرفية اللاتكيفية المبكرة حيث لم يتطرق أحد الباحثين (علي حد علم الباحثة) لدراسة علاقة اضطراب الثخصية الاعتمادية

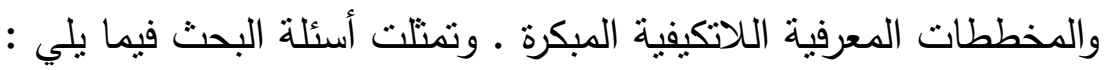
ما الفروق بين النوع الاجتماعي (الذكور - الإناث) في اضطراب الثخصيَّة الاعتمادية ؟

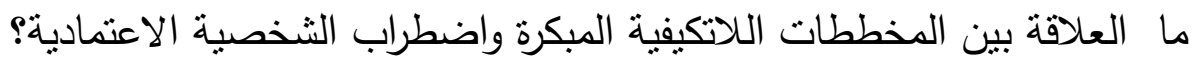
أهداف البحث يسعي البحث الحالي إلي تحقيق الأهداف التَّالية: الكثف عن العلاقة بين المخططات المعرفيَّة اللاتكيفيَّة المبكرة واضطراب الثخصية الاعتمادية. الكثفف عن الفروق بين النوع الاجتماعي ( الذكور والإناث) في اضطراب الثخصية الاعتماديَّة. أهمية البحث

$$
\text { تحددث أهمية البحث فيما يلي: }
$$

يعد موضوع دراسة اضطراب الثخصيَّة الاعتمادية موضوعًا حيويًّا، وملموسًا؛ فهذه الثخصيَّة نجدها في واقع حياتتا حتي أصبحت الاعتماديَّة سمة لأبنائنَا بدت مخاطرها جلية في مستقبل حياتهم.

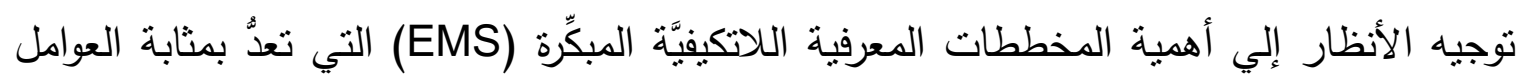
الرئيسة المهيئَة للكثير من الاضطرابات النَّفيَّة والثخصيَّة التي يعاني منها الثباب. فروض البحث

توجد علاقة ارتباطيه دالة موجبة بين اضطراب الثخصية الاعتمادية والمخططات المعرفية

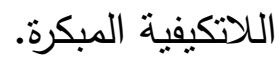
توجد فروق ذات دلالة إحصائية بين متوسطات درجات ( الذكور والإناث ) علي مقياس اضطراب الثخصية الاعتمادية. 


\section{مصطلحات البحث الإجرائية}

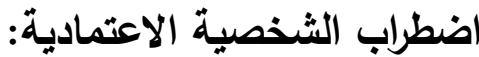

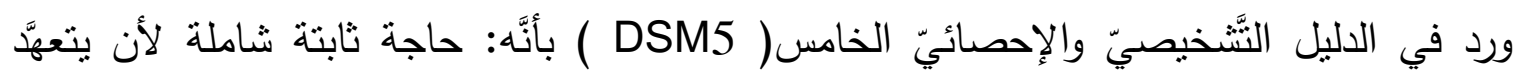

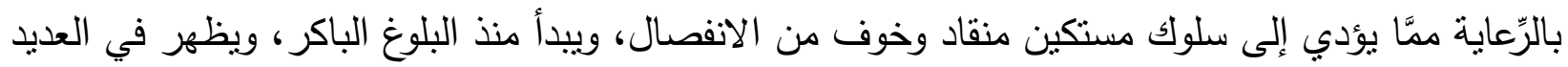

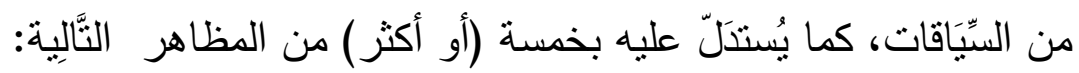

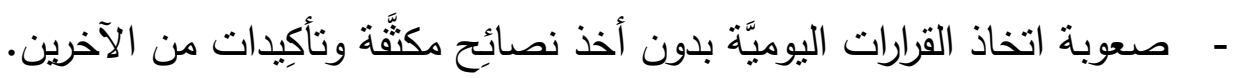

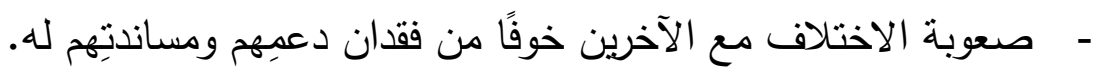

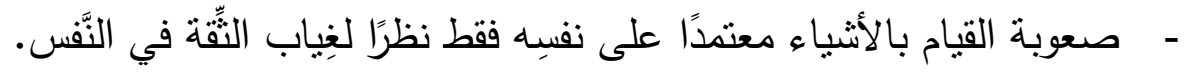

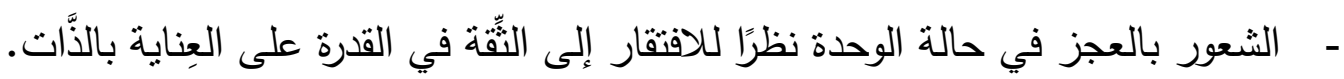

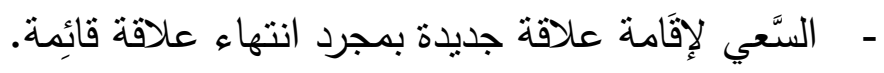

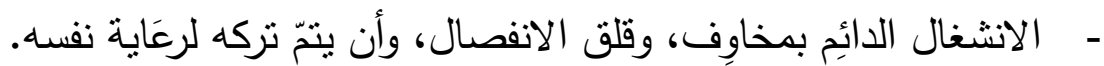

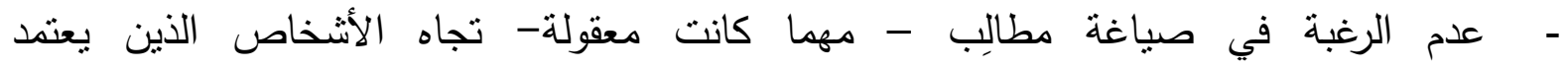
عليهم) (American Psychiatric Association, 2013).

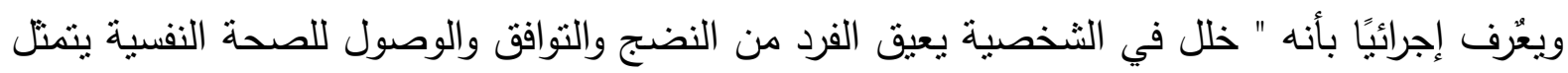

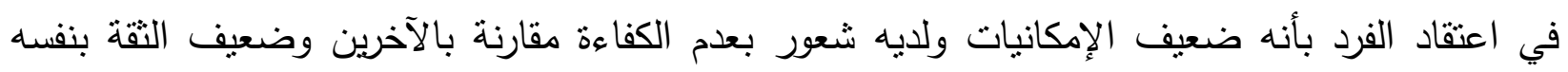

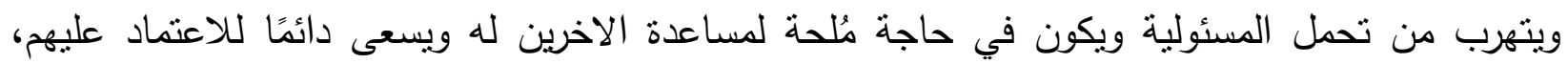

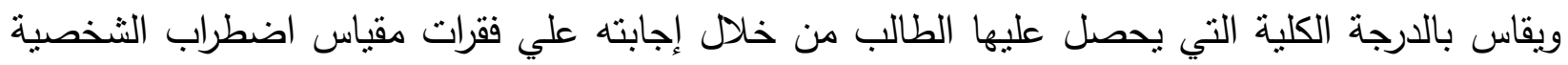

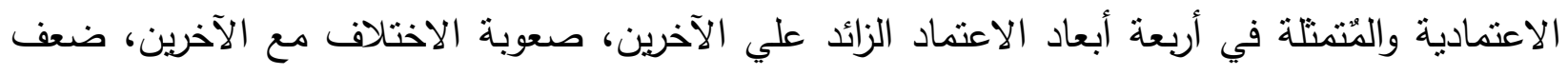

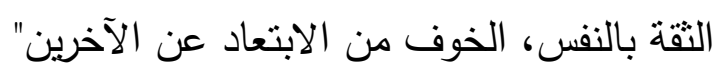
المخططات المعرفيَّة اللاتكيفيَّة المُبكرِّة:

عرف (2005) Koung, Janet, Klosko et Marjorie and Weishaar

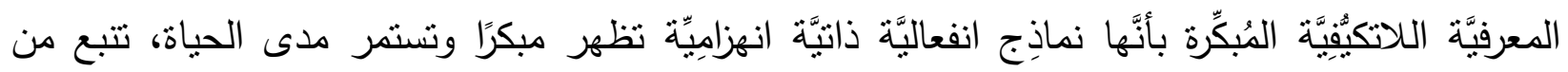

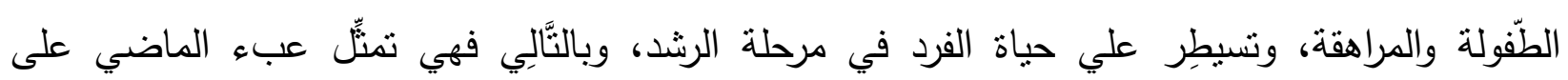

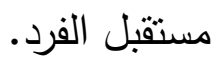

وتُقاس إجرائياً " بالدرجة الكلية التي يحصل عليها الطالب علي مقياس المخططات المعرفية اللاتكيفية

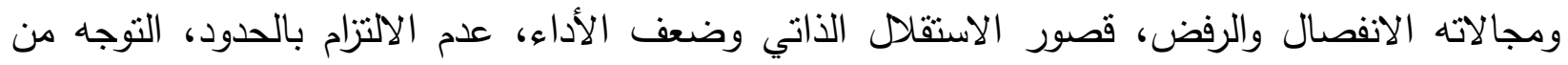

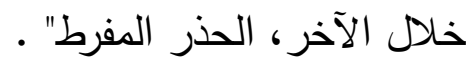




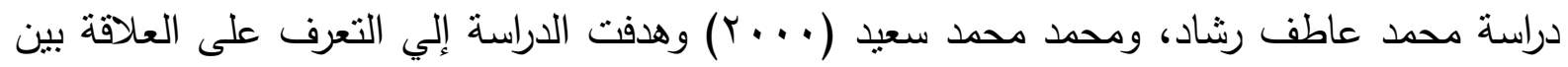

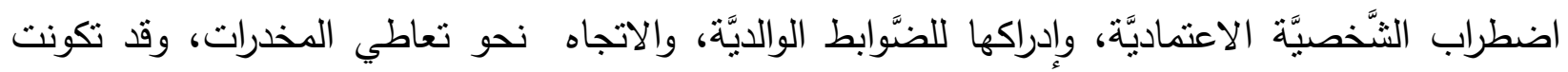

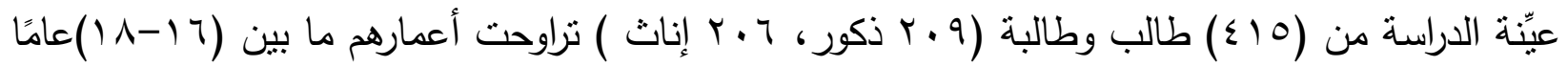

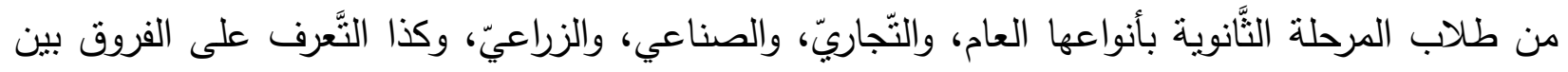
الذكور والإناث في اضطراب الثخصية الاعتماديَّة، وقد استخدم الباحثنان مقياس الاتجاه نحو تعاطِي

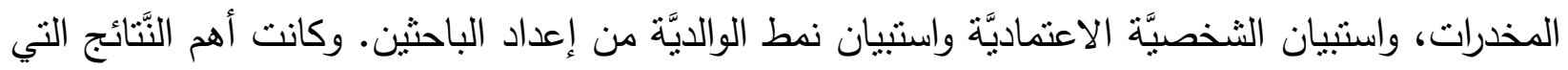
توصَّلت إليها الدراسة أنه: توجد علاقة ارتباطيَّة ذات دلالة إحصائية بين الاتِّاه نحو تعاطي المخدرات وكل التهل من نمط الوالديَّة واضطراب الثخصية الاعتماديّة لدى أفراد العينة، كما وجدت علاقة ذات دلالة إحصائية

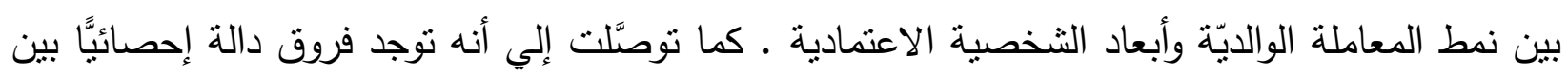
الذكور والإناث في اضطراب الثخصية الاعتماديَّة لصالح الإناث.

تناولت دراسة سلوى فهاد (10 ( ب) الاعتمادية، ونقد الذَّات السلبيّ كمتغيرات وسيطة في العلاقة بين الكماليَّة والثره العصبي لدى طالبات الجامعة، وبحث العلاقة بين اضطرابات الأكل والحالة النفسية للفرد، وتكوَّنت عينة الدراسة من (rTr) طالبة بجامعة الأميرة نورة بنت عبد الرحمن بالرياض، وشملت أدوات

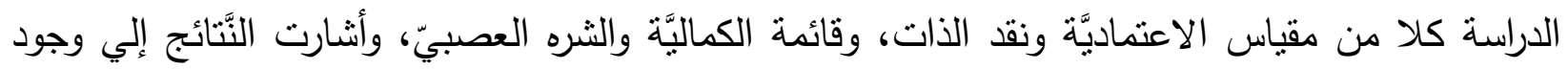

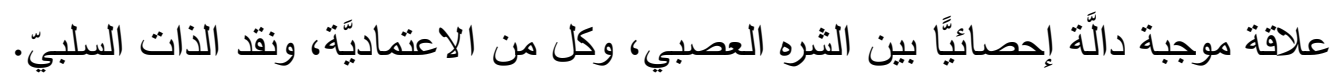

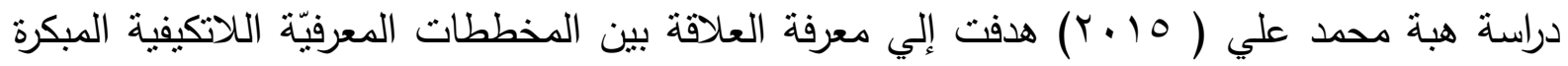

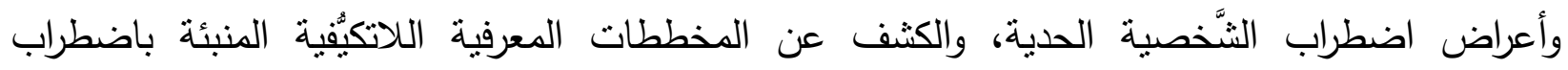

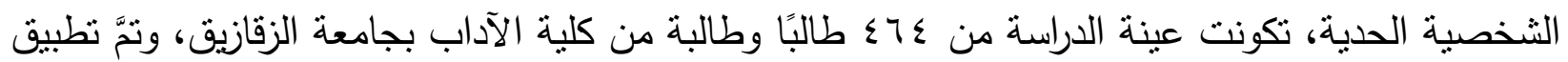
مقياس المخططات المعرفية اللاتكيفية، ومقياس اضطراب الثخصية الحدية. وأثنارت النتائج إلي وجود علاقة ارتباطيَّة دالَّة إحصائيًّ بين المخططات المعرفية اللاتكيفية، وبين أبعاد الثخصية الحديَّة لاى الذكور والإناث.

وسعت دراسة نادية محمود غنيم (Y. V) إلي الكثف عن العلاقة بين المخططات المعرفية اللاتكيفية والخبرات النفسية في الطفولة واضطراب الثخصية التجنبيَّة، والكثف عن ما إذا كانت المخططات المعرفية اللاتكيفية تعمل كمتغير وسيط بين الخبرات النَّفسية في الطفولة واضطراب الثخصية التجنبية لدى 
طلاب الجامعة، وكذللك الكثف عن الفروق بين الجنسين في كلا من المخططات المعرفية اللاتكيفُّة،

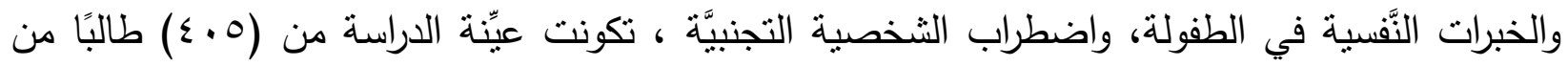
طلاب الجامعة، ونمَّ استخدام مقياس المخططات المعرفيَّة اللاتكيفَّةَ، ومقياس الخبرات النَّفسية في الطفولة، ومقياس اضطراب الثخصية التجنبية، وتوصلت النَّائج إلي وجود علاقة ارتباطيَّة عكسيَّة دالة إحصائَّا بين

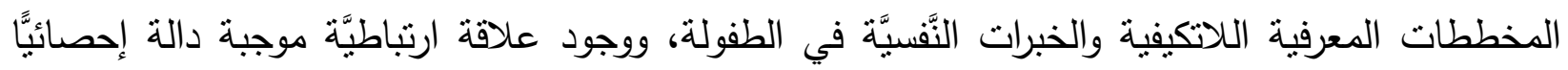
بين المخططات المعرفيَّة اللاتكيفيَّة واضطراب الثخصية التجنبية، كما وجد أن المخططات المعرفيَّة اللاتكيفيَّة عملت كمتغير وسيط بين الخبرات النَّفية في الطفولة واضطراب الثخصيَّة التَّنبية لدى طلاب الجامعة.

هدفت دراسة Hoda , David , Naysun \& Michael (2018) إلى الكثف عن العلاقة بين أنماط المخططات المعرفيَّة اللاتكيفيَّة المبكرة واضطراب الثََّخصية الحديّة لاى عيّنة من المراهقين، تكوَّنت عيّنة الدراسة من (r) من المرضي المصابين باضطراب الثخصيّة الحديَّة، وتمَّ استخدام المقابلة الاكلينيكية المنظّمة لاضطرابات الثخصية ومقياس المخططات اللاتكيفيّة. توصلت النتائج إلي وجود علاقة النئة ارتباطية موجبة دالَّة بين أنماط المخططات المعرفيَّة اللاتكيفية واضطراب الثطية الثخصيَّة الحديَّة.

\section{منهج واجراءات البحث}

- - - متخدمت الباحثة المنهج الوصفي.

- وتكونت عينة البحث الاستطلاعية من (10.1) من طلاب الفرقة الثالثة بكلية التزبية، مجتمع وعينة

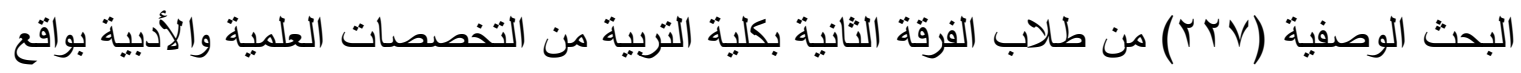

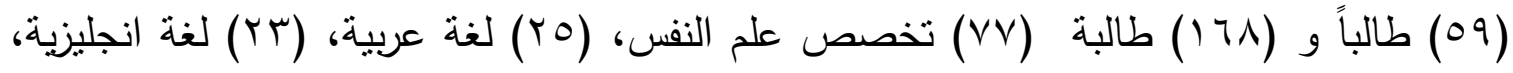

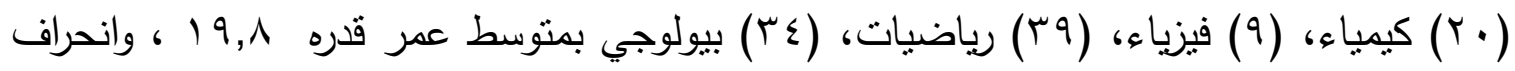

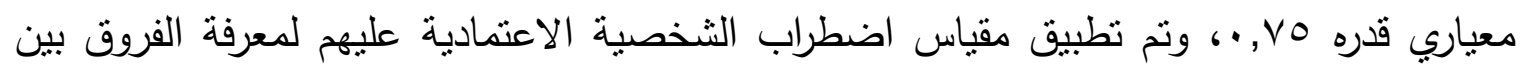
متوسطات الذكور والإناث في اضطراب الثخصية الاعتمادية، وتطبيق استنيان المخططات المعرفية اللاتكيفية المبكرة للكثف عن العلاقة الارتباطية بين اضطراب الثخصية الاعتمادية والمخططات

$$
\text { المعرفية اللاتكيفية المبكرة. }
$$

- م - استخدمت الباحثة الأدوات التالية:

$$
\text { مقياس اضطراب الثخصية الاعتمادية إعداد الباحثة }
$$

يهدف المقياس إلي قياس أبعاد الثخصية الاعتمادية تبعًا للتعريف الاجرائي لدي طلاب وطالبات كلية

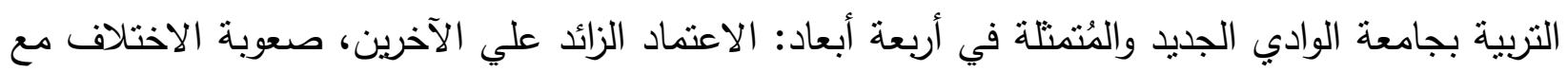


الآخرين، ضعف الثقة بالنفس، الخوف من الابتعاد عن الآخرين، ويكون المقياس من جس عبارة وتتم الإجابة

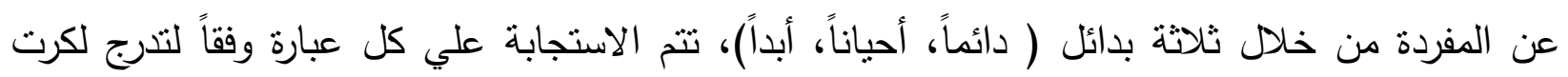

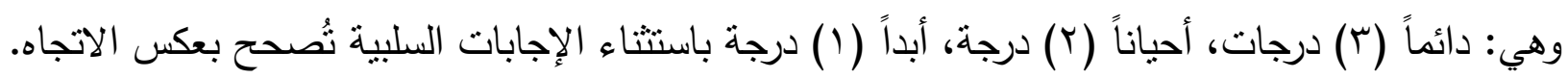

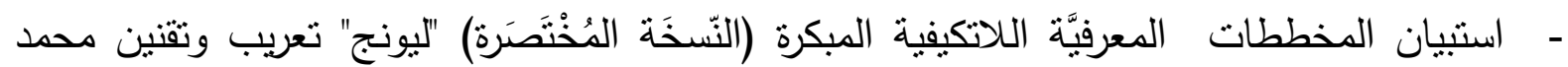

$$
\text { السيد عبد الرحمن، محمد أحمد إبراهيم(ع ( ب ب). }
$$

أعد هذا المقياس في الأصل " يونج " وهو أداة للتقرير الذاتي تعطي تقديرًا كميًا للمخططات المعرفية اللاتكيفية التي تكتسب لدي الفرد منذ مرحلة الطفولة وتثثيرها مواجهة الضغوط والمشكلات وتحدد الادراكات والسلوكيات والانفعالات والنظرة إلي المستقبل بل تحدد إلي حد كبير طبيعة المرض الذي يعاني منه الفرد،

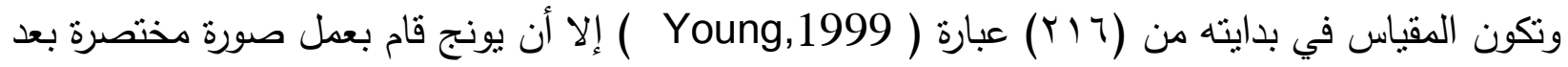
ذلك (Young and Brown(2003 يبلغ عدد عباراتها(Vo) عبارة وتغطي خمسة عشر مخططًا معرفيًا

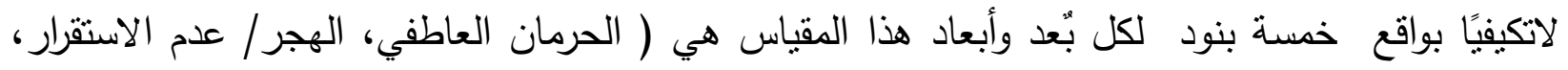

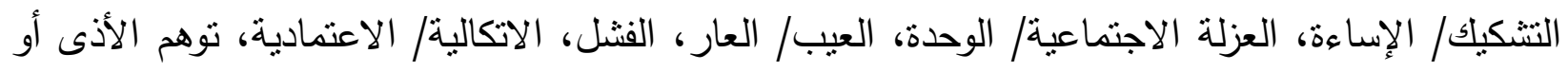

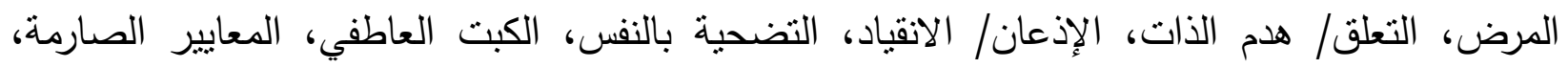
الاستحقاق/ هوس العظمة، العجز عن ضبط النفس).

قام بترجمة وتقنين المقياس ليستخدم في البيئة العربية كل من محمد السيد عبد الرحمن، محمد أحمد

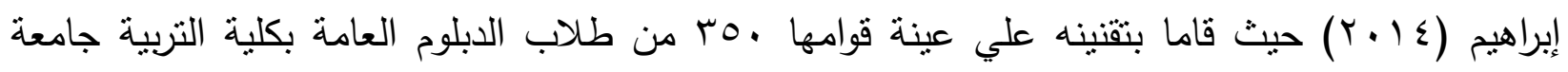
الزقازيق وتم التحقق من الخصائص السيكومترية بحساب الاتساق الداخلي للمقياس وتبت من خلاله ارتباط جميع العبارات بالأبعاد التي نتتمي إليها ثم التحقق من صدق المقياس بعدة طرق الصدق الظاهري والصدق

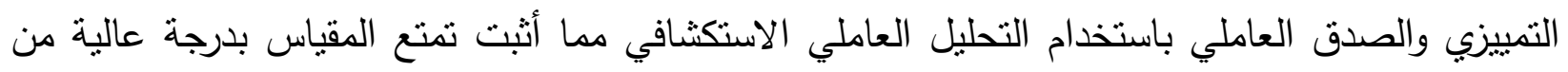

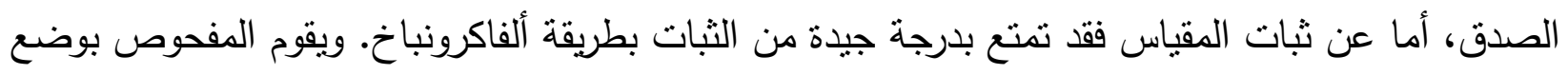

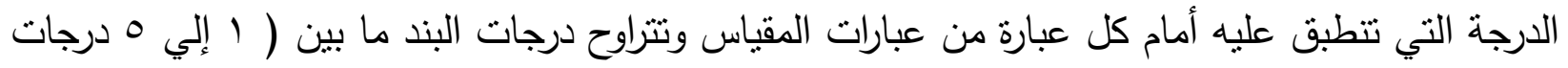

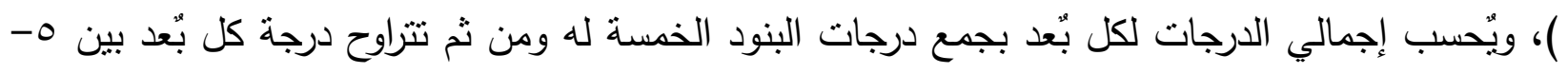

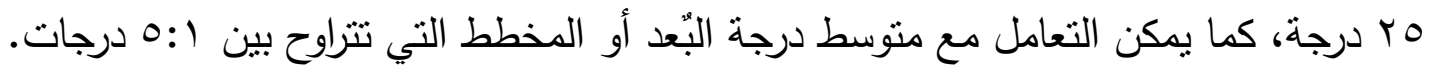




\section{خطوات بناء المقياس في البحث الحالي: تحديد هدف المقياس:}

تم بناء هذا المقياس بهدف قياس أبعاد الثخصية الاعتمادية لدي طلاب وطالبات كلية التربية جامعة الوادي

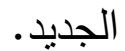

\section{تحديد مصادر بناء عبارات المقياس:}

قامت الباحثة بالاطلاع علي الأطر النظرية النفسية والبحوث والدراسات السابقة والتي وضحت ماهية الثخصية الاعتمادية وأبعادها وصفاتها، والاطلاع علي عدد من المقاييس التي أستخدمت في البحوث والدراسات العربية والأجنبية ذات الصلة بالدراسة الحالية منها:

مقياس الاعتمادية إعداد حسين علي (T . . Y) وقد اعتبر المقياس بعدًا فرعيًا لاستبيان الخبرات الاكتئابية،

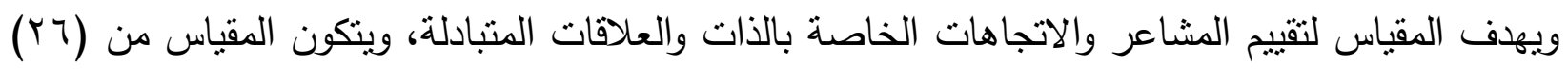

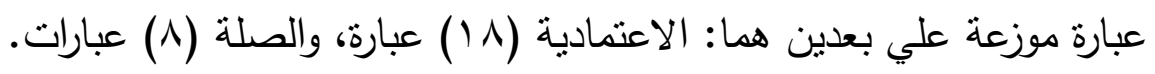

مقياس انحراف الثخصية إعداد (2003) Bedford \&Deary ويتكون هذا المقياس من ثلاثة أبعاد رئيسة

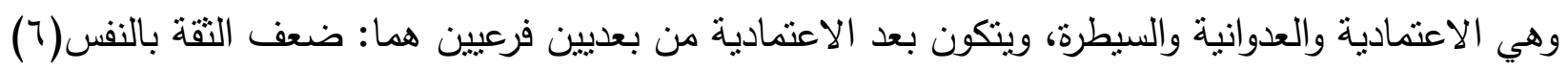
عبارات، والاعتماد الزائد علي الاخرين(آ) عبارات.

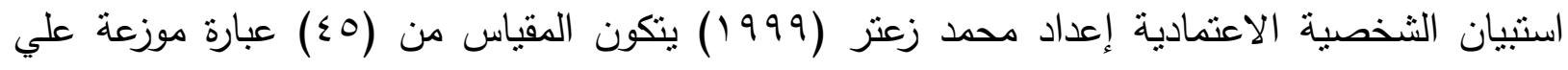

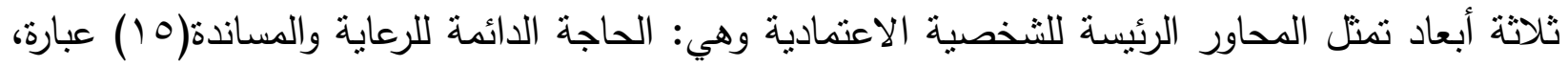
الافتقار إلي النضج والتهرب من المسئولية(0 10) عبارة، التعلق الزائد والخوف من الانفصال(10 (1) عبارة.

مقياس الثخصية إعداد أحمد محمد عبد الخالق(997 ( ) مقياس الثخصية إعداد رشا علي، مديحة منصور (11) ( + (1).

وبمراجعة المقاييس السابقة اتضح عدم ملائمة بعض المقاييس للعينة الحالية حيث صُممت للتطبيق علي طلاب المرحلة الثانوية كما في استبيان الاعتمادية لمحمد عاطف، محمد محمد(999 () )، عدم ملائمة مقياس

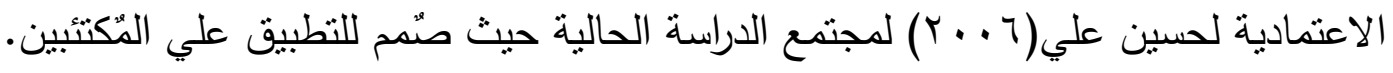




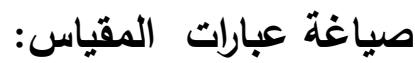

بالاعتماد علي الخطوات السابقة تم صياغة عبارات المقياس، وقد رُوعي في الصياغة أن تكون كل

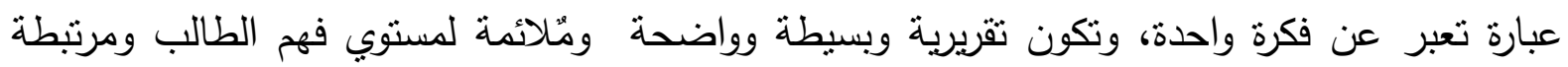
بالواقع.

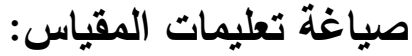

تم إعداده بما يتتاسب مع الفئة العمرية لطلاب الكلية، ولا يوجد وقت محدد لتطبيق المقياس، وتتم الإجابة عن المفردة من خلا ثلاث بدائل ( دائماً، أحياناً، أبداً).

طريقة تصحيح المقياس:

تتم الاستجابة علي كل عبارة وفقاً لطريقة لكرت وهي: دائماً (r) درجات، أحياناً (r) درجة، أبداً (1) درجة باسنثناء الإجابات السلبية تُصحح بعكس الاتجاه، بحيث تكون الدرجة القصوى للمقياس (1 • ( )

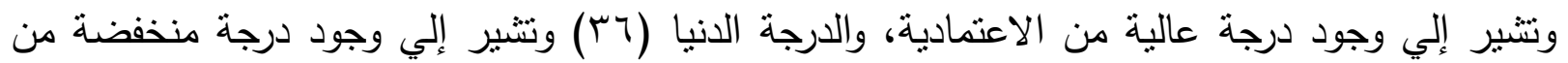
الاعتمادية.

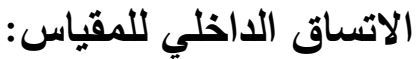

للتحقق من الاتساق الداخلي نم حساب معامل ارتباط (بيرسون) بين كل عبارة من عبارات المقياس بالدرجة الكلية للبعد الذي تتنمي إليه، وذلك لمعرفه ددى ارتباط واتساق عبارات المقياس بالدرجة الكلية لكل بعد، والجدول (1) يوضح النتائج: 


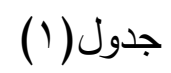

معاملات الاتساق الداخلي بين العبارات واللارجة الكلية للبعد الذي تنتمي إليه (ن=، ه 1)

\begin{tabular}{|c|c|c|c|c|c|c|c|}
\hline الارتباط معامل & الآلخوف من & الارتباط معامل & بالنفس & معامل الارتباط & الاختلاف & معامل الارتباط & الآلائد علي الآخرين \\
\hline " $\vee १ 9$. & IV & $" \wedge \leqslant 9$. & 1 & "*ит. & 9 & "*ห५. & $r$ \\
\hline${ }^{* * *} \wedge 11$. & 19 & "V१9. & $r$ & $" \wedge 99$. & 9 & "**rv. & 0 \\
\hline *** ^ฯะ. & $r$ & 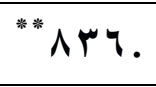 & $\varepsilon$ & "*N" & Ir & $" \wedge \bullet$. & $\Lambda$ \\
\hline "*** $\vee \wedge$. & $r v$ & $" \wedge 0 \leqslant$. & v & "* Arv. & 10 & $" \wedge \leqslant \wedge$. & 1. \\
\hline${ }^{* * *} \wedge \mid r$. & m & " $\vee \wedge १$. & 14 & ${ }^{* *} \wedge \vee \leq$. & $r \varepsilon$ & "** & 11 \\
\hline${ }^{* * *} \vee \leq \varepsilon$ & $r r$ & "VY & $1 \leqslant$ & $* q .0$. & $r$. & $" \wedge \wedge$ " & 17 \\
\hline${ }^{* * *} \wedge . \bullet$. & ro & "vir. & 11 & "**ห^. & $r \varepsilon$ & "** $\wedge \vee r$. & Y \\
\hline & & $" \vee \vee \vee \wedge$. & $r$. & & & $" \wedge i v$. & ry \\
\hline & & "* Arr. & rr & & & "* Arv. & ru \\
\hline & & $" \wedge 1$. & ro & & & "vru. & rq \\
\hline & & $" \wedge 14$. & rr & & & & \\
\hline & & "vVr. & q & & & & \\
\hline
\end{tabular}

$$
\text { ** دال عند (1, *. }
$$


جدول(r)

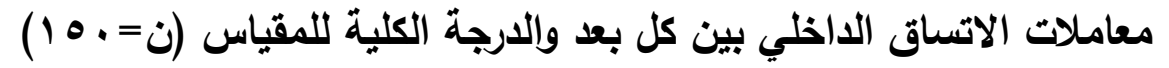

\begin{tabular}{|c|c|c|c|c|}
\hline الآبتعاد عن من & ضالنفس الثقة & صعوية الاختلاف & الآلائد علي الآخرين & البعد \\
\hline${ }^{* *}$.VYO & ${ }^{* *} . \vee q$. & $" * \vee \vee 9 \wedge$ & "** . V० & معامل \\
\hline
\end{tabular}

يتضح من الجدول رقم (Y، (Y) بأن عبارات مقياس اضطراب الثخصية الاعتمادية تتمتع

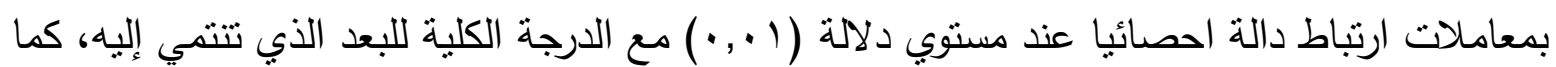

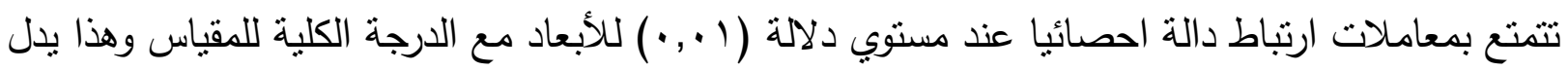

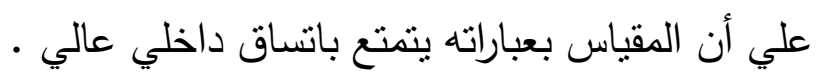
الخصائص السيكومترية لمقياس الثخصية الاعتمادية: صدق المقياس صدق التحليل العاملي الاستكشافي : تم إجراء التحليل العاملي Factorial Analysis من الدرجة الأولى لمقياس اضطراب الثخصية

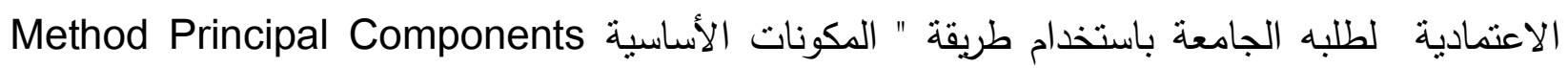
التي اقترحها هوتلنج Hottelling عام سبو 19 وهي من أفضل طرق التحليل العاملي من حيث الدقة ويستخلص فيها كل عامل أقصى تباين ممكن ، كما تم إجراء التذوير المتعامد للمحاور (العوامل ) باستخدام

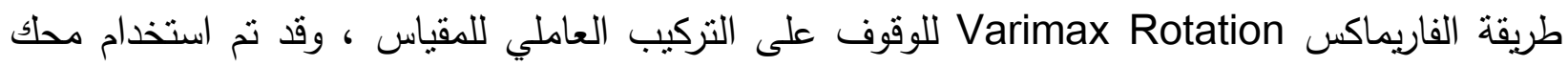

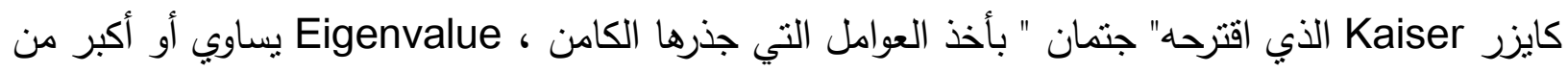

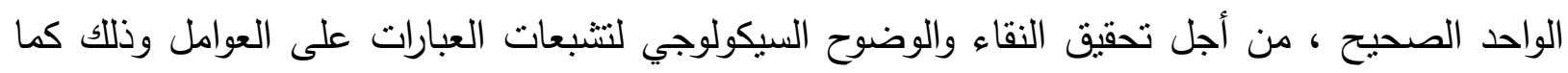
ذكر صفوت فرج (1991، ؟ Y) بواسطة حزمة البرامج الإحصائية في العلوم الاجتماعية (SPSS 26) ذلك على عينة التقنين ،المكونة من ( (10 ) طالباً وطالبة. أ - الإبقاء على العوامل التي جذرها الكامن Eigenvalue

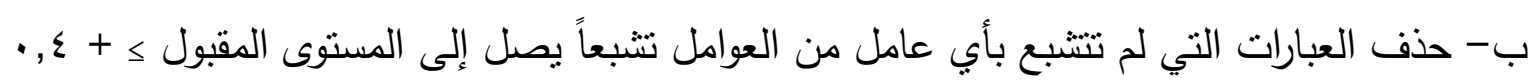

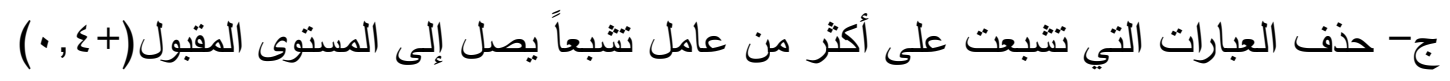
د- حذف بعض العبارات تبعاً لحذف العامل الذي تشبعت عليه. 
هـ - حذف العوامل التي تتبعت بها عبارة واحدة أو عبارتان فقط تتبعاً مقبولاً ، وقد نت الإبقاء على العوامل

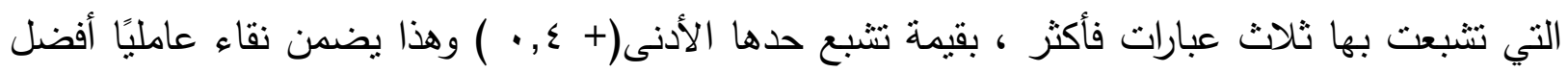

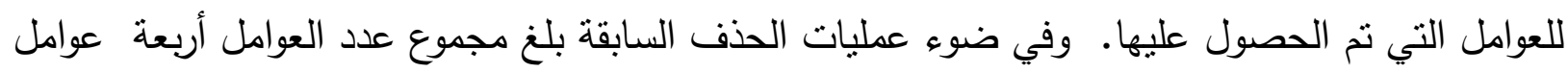

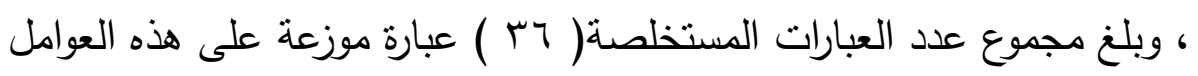

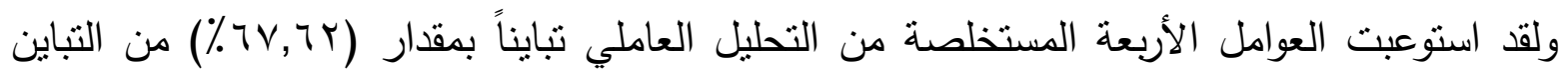

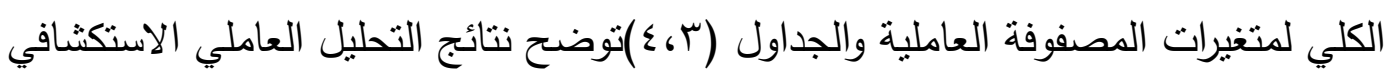

جدول (r)

قيم الثيوع لمقياس اضطراب الثخصية الاعتمادية

\begin{tabular}{|c|c|c|c|c|c|c|c|}
\hline قيم الشيوع & العبارة & قيم الثشيوع & العبارة & قالاشم الثيوع & العبارة & قيم الشيوع أو & العبارة \\
\hline צ & 1 & . 110 & YI &. $\mathrm{rVA}$ & 11 & .201 & 1 \\
\hline . & rr & .791 & rr & . VIA & Ir & ك & $r$ \\
\hline & rr & Gru & rr & & $\mu$ & . $0 \leqslant 1$ & $r$ \\
\hline דr. & & .799 & $r \varepsilon$ & & $1 \varepsilon$ &.$\vee 1 \wedge$ & $\varepsilon$ \\
\hline .7V0 & ro & $.7 \vee \wedge$ & ro & $. v \leq 1$ & 10 & .VYV & 0 \\
\hline \multirow[t]{5}{*}{.7 .9} & & .7 .0 & T & سות. & 17 &.$v \cdot q$ & 7 \\
\hline & &.$v \cdot \Lambda$ & $r V$ &.$v \ldots$ & IV &.$V V \varepsilon$ & $v$ \\
\hline & & $. V \leq$. & rA & . & 11 & . $7 \leqslant 0$ & $\Lambda$ \\
\hline & & & rq & 7 & 19 & . V78 & 9 \\
\hline & & .var & $r$. & . & $r$. &.$\vee १ \wedge$ & 1. \\
\hline
\end{tabular}


جدول (£)

التتبعات وقيم الجذر الكامن ونسبة التباين المفسرة للعوامل بعد التدوير

\begin{tabular}{|c|c|c|c|c|}
\hline \multicolumn{4}{|c|}{ العوامل المستخرجة } & \multirow{2}{*}{ العبارات } \\
\hline الرابع & الثالث & الثاني & الأول & \\
\hline & & & $\Lambda \leq 4$. & v \\
\hline & & & $\Lambda \leq r$. & 1 \\
\hline & & & Art. & $\varepsilon$ \\
\hline & & & AIr. & rr \\
\hline & & & $\Lambda \cdot r$. & ro \\
\hline & & & A. 1 . & rr \\
\hline & & & จ११. & $r$ \\
\hline & & & $V \vee \leq$. & ir \\
\hline & & & VVr. & r \\
\hline
\end{tabular}

تابع جدول (ع) التشبعات وقيم الجذر الكامن ونسبة التباين المفسرة للعوامل بعد التذوير

\begin{tabular}{|c|c|c|c|c|c|}
\hline & & & &.$V \otimes V$ & $1 \leq$ \\
\hline & & & & $.7 \leqslant 0$ & 11 \\
\hline & & & & $.0 V \varepsilon$ & $r$. \\
\hline & & & $. \wedge 9 \leqslant$ & & rI \\
\hline & &.$\wedge \vee q$ & & 17 & \\
\hline & & $. \wedge \leqslant Y$ & & $r \wedge$ & \\
\hline & & $. \wedge \leq 1$ & & 0 & \\
\hline & & $. V \leqslant V$ & & $\wedge$ & \\
\hline & & $. V \leq r$ & & Y & \\
\hline & & .VTV & & rq & \\
\hline
\end{tabular}




\begin{tabular}{|c|c|c|c|c|}
\hline & & .71. & & $r$ \\
\hline & & $.0 Y 1$ & & 11 \\
\hline &.$\wedge \wedge 1$ & & & $r$. \\
\hline & .109 & & & 10 \\
\hline & .100 & & & 9 \\
\hline & $. \wedge \leq 1$ & & & \\
\hline & .Аrی & & & Ir \\
\hline &.$\wedge r V$ & & & 7 \\
\hline &.$A \cdot V$ & & & $r \varepsilon$ \\
\hline צ & & & & YV \\
\hline צ & & & & IV \\
\hline.$\wedge r$. & & & & rr \\
\hline.$\wedge 1 \wedge$ & & & & ק \\
\hline.$\Lambda \cdot \varepsilon$ & & & & r \\
\hline$. V \leq$. & & & & $r 1$ \\
\hline.$v r q$ & & & & 19 \\
\hline$P, 719$ & $0, \cdot \varepsilon$. & צ & $9,00 \wedge$ & الكامن \\
\hline $1 \cdot, 0 \leq$ & $\begin{array}{c}1 \leq, \ldots \\
1\end{array}$ & $\begin{array}{c}\text { IV,. } \\
1\end{array}$ & $r 7,001$ & نالتباين \\
\hline
\end{tabular}

يتضح من جدول (T،؛) أن التحليل العاملي لعبارات مقياس اضطراب الثخصية الاعتمادية قد أسفر عن

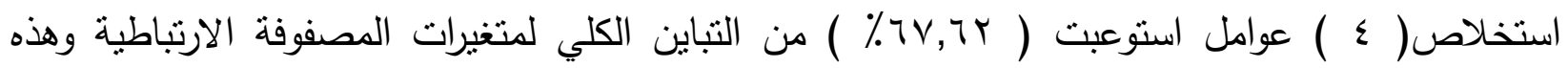
العوامل هي:

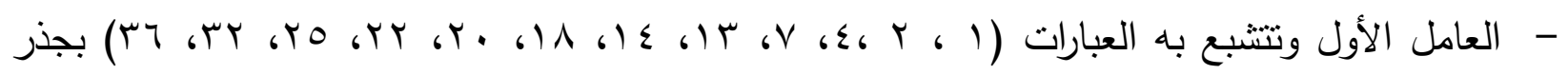

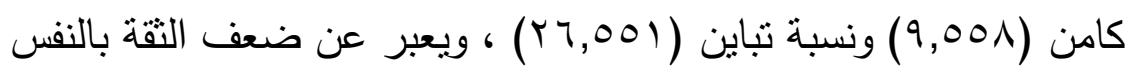

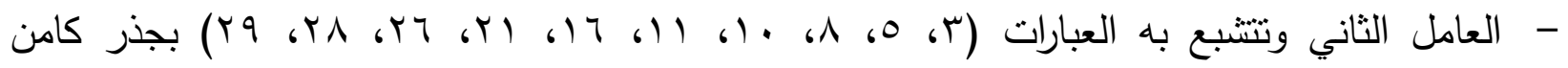

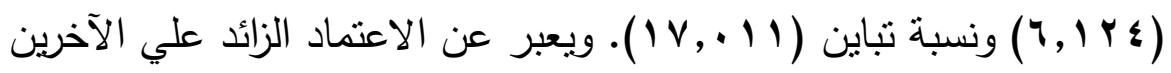




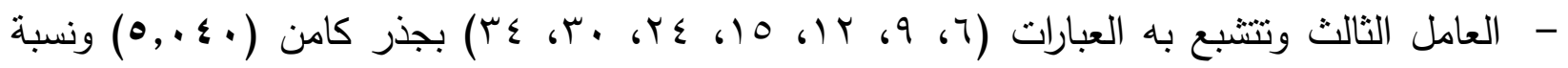
تباين (1 . ., ؛ 1). ويعبر عن صعوبة الاختلاف مع الآخرين

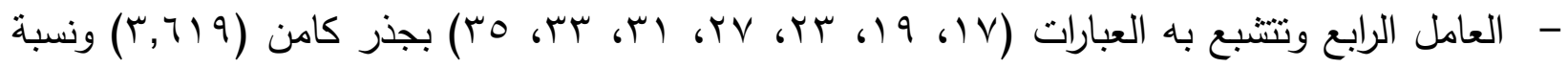
تباين (ـه, • (). ويعبر عن الخوف من الابتعاد والانفصال عن الآخرين

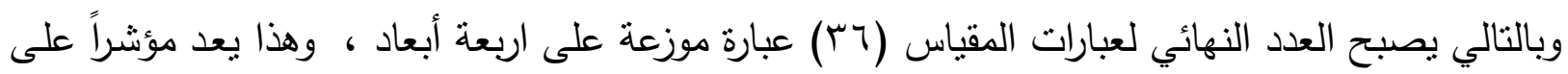
صدقة - ثانياً : ثبات المقياس - الثبات بطريقه ألفا-كرو نباخ Alpha ، والتجزئة النصفية ، وجتمان:

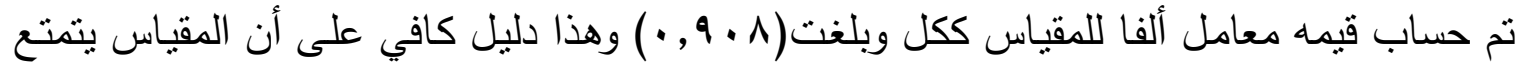
بمعامل ثبات عالي، كما تم حساب معامل الثبات وحساب الثبات أيضًا بمعادلة جتمان وأظهرت النتائج أن

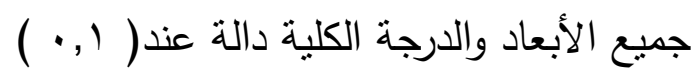
جدول (0)

معامل الثبات ألفا-كرو نباخ Alpha ، والتجزئة النصفية ، وجتمان لكل بعد واللارجة الكلية للمقياس

\begin{tabular}{|c|c|c|c|c|c|}
\hline الارجة & الخوف من الابتعاد & ضالنفف & صعوية الاختلاف & الآزائد علمي الآخرين & \\
\hline$\cdot, 9 \cdot 1$ & $\cdot, 9 \cdot \varepsilon$ &., $9 \mu \mathrm{V}$ &., $9 \leq 0$ & $.9 \leq r$ & ألقا \\
\hline$\cdot, \wedge \wedge 1$ &., 910 &., 941 & $\cdot, 9 \leq 0$ & .9919 & سييرمان براون \\
\hline$\cdot, \wedge \wedge 1$ & $\cdot, \wedge a r$ &., $94 \wedge$ &., $9 r A$ & $.91 \leqslant$ & جتمان \\
\hline
\end{tabular}

مقياس المخططات المعرفيَّة اللاتكيفية المبكرة (النّسخَة المُخْنَصَرَ) "ليونج" تعريب وتقنين محمد السيد عبد

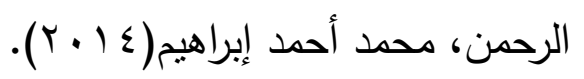

الخصائص السيكومترية لمقياس المخططات المعرفية اللاتكيفية:

الاتساق الاخلي للمقياس:

للتحقق من الاتساق الداخلي تم حساب معامل (بيرسون) بين كل عبارة من عبارات كل بعد والدرجة الكلية للبعد الذي نتمي إليه، وذلك لمعرفه مدى ارتباط واتساق عبارات المقياس، والجدول (؟) يوضح 
جدول(T)

معاملات الاتساق الداخلي بين العبارات والارجة الكلية للبعد الأي تتنمي إليه (مجال الرفض والانفصال) $(10 \cdot=\dot{0})$

\begin{tabular}{|c|c|c|c|c|c|c|c|c|c|}
\hline معامل & والعيب & الارتباط & الاجتماعية العزلة & الارتباط & التثكيك/الاساءة & الارتباط & الإهمال/علدم & الارتباط معامل & العاطفي \\
\hline $\begin{array}{l}\text { va.. } \\
\text { *** }\end{array}$ & 1 & vio. & 1 & OrA. & 1 & 7.0. & 1 & $\cdot, \wedge \mid r$ & 1 \\
\hline $\begin{array}{l}\qquad \vee \wedge . \\
\cdots\end{array}$ & r & vo.. & r & vio. & r & $\begin{array}{l}\text { ivr. } \\
\text { ". }\end{array}$ & r & $\cdot, \vee \vee \wedge \varepsilon$ & r \\
\hline $\begin{array}{l}\text { vor. } \\
\text {.. }\end{array}$ & $r$ & TVO. & $r$ & ror. & r & $\because \wedge 9$. & $r$ & $\cdot, \vee \vee \wedge \varepsilon$ & $r$ \\
\hline Ar. & $\varepsilon$ & **r. & $\varepsilon$ & IVV. & $\varepsilon$ & $7 \leq$ & $\varepsilon$ & $* * \diamond \vee q$. & $\varepsilon$ \\
\hline Ar. & 0 & $\begin{array}{l}\text { VTr. } \\
\text { *** }\end{array}$ & 0 & 790. & 0 & $\leq 0 \leq$. & 0 & $" 47$. & 0 \\
\hline
\end{tabular}

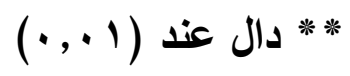

جدول(V) معاملات الاتساق الداخلي بين العبارات والدرجة الكلية للبعد الأي تنتمي إليه ( مجال قصور الاستقلال الأتي) (ن=) •

\begin{tabular}{|c|c|c|c|c|c|c|c|}
\hline معامل & وهدم الأات & الارتباط معامل & المرض أو الأذى & الارتباط معامل & الاعتكالية & معامل الارتباط & الفشل \\
\hline$* * .7 . r$ & 1 & $* * . \Delta q \mu$ & 1 & $* * . \Delta q \mu$ & 1 & $* * . \diamond \wedge \wedge$ & 1 \\
\hline **.Vr. & $r$ & $* * . \neg \wedge r$ & $r$ & $* * . \neg \wedge r$ & $r$ & $* * . V \cdot r$ & $r$ \\
\hline${ }^{* * *} .79$. & r & *** ..$๑ 1$ & r & *** . .01 & r & ${ }^{* * *} . V Y Y$ & r \\
\hline *** . \^ & $\varepsilon$ & *** . & $\varepsilon$ & *** . & $\varepsilon$ & ه & $\varepsilon$ \\
\hline$* * * \wedge \Lambda$. & 0 & ${ }^{* * *} \vee \wedge \mu$. & 0 & ${ }^{* * *} \vee \wedge \mu$. & 0 & *** $V \odot Y$. & 0 \\
\hline
\end{tabular}

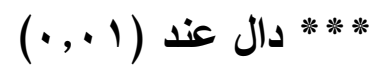


جدول(^)

معاملات الاتساق الاخظلي بين العبارات والدرجة الكلية للبعد الذي تتنمي إليه ( مجال التوجه من خلال الاخر والحذر المفرط (ن= • 10 )

\begin{tabular}{|c|c|c|c|c|c|c|c|}
\hline معامل الارتباط & الصعارمـة النقاق & معامل الارثباط & الكبث & معامل الارثباط & التضحية & معامل & الإذان أنقياد \\
\hline ** ๆ๑ & 1 & *** & 1 & ${ }^{* * *} \vee \vee \neg$. & 1 & ${ }^{* *} r \wedge r$. & 1 \\
\hline . & $r$ & ${ }^{* * *} \vee Y Y$. & $r$ & ${ }^{* * *} V I Y$. & $r$ & ${ }^{* * *} \nsucceq \vee \varepsilon$. & $r$ \\
\hline$* * 7 \vee 7$. & $r$ & ${ }^{* * *}$ TV.. & $\mu$ & ${ }^{* * * *} V \cdot V$. & $r$ & *** $\vee \curlyvee 9$. & $r$ \\
\hline *** $\vee 79$. & $\varepsilon$ & ${ }^{* * *} \curlyvee \wedge$. & $\varepsilon$ & *** \^乏. & $\varepsilon$ & *** ๆ ๆ0. & $\varepsilon$ \\
\hline 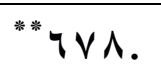 & 0 & ${ }^{* * *} \vee \leq \varepsilon \leq$. & 0 & ${ }^{* * *} \nearrow \leq Y$. & 0 & $* * \circ \wedge$ & 0 \\
\hline
\end{tabular}

جدول(9)

معاملات الاتساق الااخلي بين العبارات والدرجة الكلية للبعد الذي تتنمي إليه ( مجال عدم الالتزام

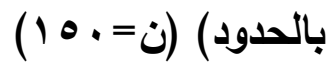

\begin{tabular}{|c|c|c|c|c|}
\hline معامل الارتباط & العجز عن ضبط الذات & معامل الارتباط & العظمة & |لاستخفاف| \\
\hline$\cdot v \cdot r^{* *}$ & 1 & ".vN1 & & 1 \\
\hline $.7 r \Lambda^{* *}$ & r & $.4 \Lambda \Lambda^{* *}$ & & $r$ \\
\hline $.70 \Lambda^{* *}$ & $r$ &.$\vee \vee \Lambda^{* *}$ & & $r$ \\
\hline $.7 r \Lambda^{* *}$ & $\varepsilon$ &.$v \cdot q^{* *}$ & & $\varepsilon$ \\
\hline$. v \leq £ " *$ & 。 & .VYI"* & & 。 \\
\hline
\end{tabular}

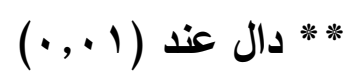




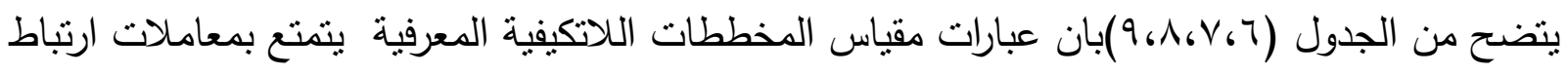
داله إحصائيا عند مستوي (1 .,.•)مع الدرجة الكلية للبعد الذي تتنمي إليه ، وهذا يدل على أن المقياس بعبارته يتمتع باتساق داخلي عالي •

: Alpha - الثبات بطريقه ألفا-كرونباخ نم حساب قيمه معامل ألفا للمقياس لكل بعد فرعي وكل مجال وجاءت قيم معامل الفا مرتفعة جميعها أعلي من V, · ، وهذا دليل كافي على أن المقياس يتمتع بمعامل ثنات عالي ، ويتضح ذلك من خلال

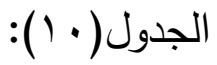

\section{جدول (1.)}

معامل الثبات بطريقة ألفا كرونباخ لكل بعد والارجة الكلية للمجال

\begin{tabular}{|c|c|c|}
\hline معامل الفا & البعد الفرعي & المجال الرئيس \\
\hline$\cdot, V M I$ & الحرمان العاطفي & \multirow[t]{6}{*}{ مجال الانفصال والرفض } \\
\hline$\cdot, \wedge 1 \leq$ & الإهمال/عدم الاستقرار & \\
\hline$\cdot, \vee \vee १ ०$ & التشكيك/الاساءة & \\
\hline$\cdot, \Lambda \cdot 1$ & العزلة الاجتماعية & \\
\hline$\cdot, \wedge r r$ & العيب والعار & \\
\hline., 940 & مجال الانفصال والرفض & \\
\hline
\end{tabular}

\begin{tabular}{|c|c|c|}
\hline$\cdot, \Lambda Y r$ & 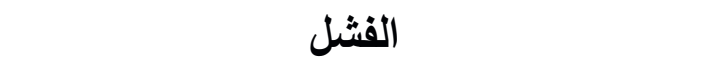 & \multirow{5}{*}{ مجال قصور الاستقلال } \\
\hline$\cdot, V Y r$ & الاتكالية الاعتمادية & \\
\hline$\cdot, v \otimes 0$ & توهم المرض او الأذى & \\
\hline$\cdot, \vee \wedge \diamond$ & التعلق وهدم الذات & \\
\hline$\cdot 914$ & مجال قصور الاستقلال الذاتي وضعف الاداء & \\
\hline$\cdot, \Lambda \leq r$ & الإذعان أو الانقياد & \multirow[t]{2}{*}{ مجال التوجه نحو الآخر } \\
\hline$\cdot, \wedge) \leqslant$ & التضحية بالذات & \\
\hline
\end{tabular}




\begin{tabular}{|c|c|c|}
\hline$\cdot, 9 \cdot \varepsilon$ & مجال التوجه نحو الآخر & \\
\hline$\cdot, \wedge \vee \diamond$ & الكبت العاطفي & \multirow{3}{*}{ الانفعالي/الحذر } \\
\hline$\cdot, \wedge \perp V$ & المعايير الصارمة/ النفاق & \\
\hline$\cdot, 91 r$ & مجال الكف الانفعالي/الحذر & \\
\hline$\cdot, \vee \wedge \wedge$ & الاستخفاف/ هوس العظمة & \multirow{3}{*}{ الحدود المختلة وعدم } \\
\hline$\cdot, \vee \vee 0$ & العجز عن ضبط الذات & \\
\hline$\cdot, 9 \cdot v$ & الحدود المختبة وعدم الوضوح & \\
\hline
\end{tabular}

\section{نتائج البحث ومناقثتها :

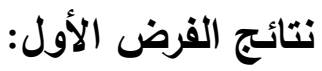

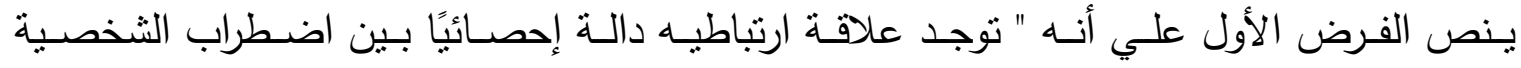

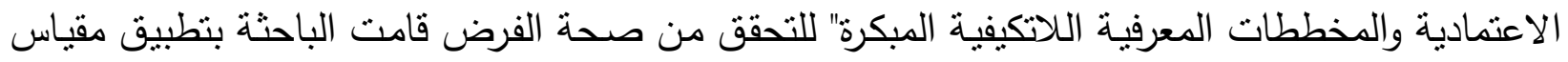
الثخصية الاعتماديـة ومقيـاس المخططـات المعرفيـة اللاتكيفيـة المبكرة واستخدمت الباحثة معامل ارتبـاط بيرسون وجاءت نتائجه كما يوضحها الجدول (1) جدول (11)

معاملات الارتباط بين اضطراب الثخصية الاعتمادية والمخططات اللاتكفية المعرفية

\begin{tabular}{|c|c|c|c|c|c|c|}
\hline \multicolumn{5}{|c|}{ الثخصية الاعتمادية } & \multicolumn{2}{|c|}{ المخططات اللاتكيفية } \\
\hline 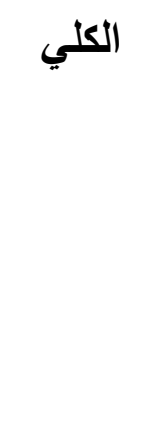 & الآل الآخوف & ضالنفف & الاختلاف & الآلزائد عثي & المخططات & المجالات \\
\hline$* * V \leq \leq$ & $* * .7 V 7$ & $* .0 \wedge r$ & ${ }^{* *} . \vee V Y$ & "**A & الحرمان العاطقي & مجال \\
\hline$* .7 .0$ & $* * .797$ & "*.7VI & "* & "*vrl & الإهمال/عدم الاستقرار & الانفصال \\
\hline
\end{tabular}




\begin{tabular}{|c|c|c|c|c|c|c|}
\hline$* * . \vee 1 \leq$ & ${ }^{* *} . V \leq V$ & $* .911$ & ".VYI & $* * \wedge \leq V$ & التشكيك/الاساءة & \multirow[t]{4}{*}{ والرفض } \\
\hline$* .279$ & ${ }^{* *} \cdot \Lambda \cdot \Lambda$ & $* * v \leq q$ & "*vVI & "**. & العزلة الاجتماعية & \\
\hline$* * v \cdot q$ & 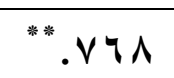 & $* * .7 \leq 9$ & $* * v r q$ & $* * \wedge \wedge q$ & العيب والعار & \\
\hline$*$ *VIV & "*.TVY & $* * v \cdot v$ & $" * .1 .0$ & $* * . V \leq Y$ & مجال الانفصال والرفض & \\
\hline$* * \wedge \wedge$. & $\begin{array}{c}{ }^{* *} \cdot V q r^{*} \\
*\end{array}$ & $* * \vee \vee \wedge \wedge$ & $* * .91 \leq$ & "*. & الفشل & \multirow{5}{*}{ لألتي وضال قصور } \\
\hline$* * . \wedge \leqslant r$ & "*.VYO & "*. . 41 & "**.179 & $" v * v \leq q$ & الاتكالية الاعتمادية & \\
\hline "* . & "**.VTr & " & "*. & $" .717$ & توهم المرض او الأذى & \\
\hline$* * \cdot v \cdot \Lambda$ & $* * \cdot V \cdot Y$ & $" .91 Y$ & ". .VYO & $* * . \vee \diamond 0$ & التعلق وهدم الذات & \\
\hline$* * . \wedge 91$ & $* * . \vee \diamond \wedge$ & $* * .791$ & $* * . \wedge r q$ & "**.var & مجال قصور الاستقلال & \\
\hline $.99 \Lambda^{* * *}$ &.$\vee 9 q^{* * *}$ & $.9 r v^{* *}$ &.$V \mu q^{* * *}$ &.$\vee 9 V^{* * *}$ & الإذعان أو الانقياد & \multirow{3}{*}{ نحو الآخر التوجه } \\
\hline $.117^{* * *}$ & $.9 q^{* * *}$ & $. V 1 \leq * *$ & $. \wedge \leqslant 0^{* * *}$ & $.117^{* * *}$ & التضحية بالذات & \\
\hline$. \wedge \leq 0^{* * *}$ &.$\wedge 17^{* * *}$ & .VYO"* &.$v \varepsilon \varepsilon^{* * *}$ &.$v \diamond \Delta^{* * *}$ & مجال التوجه نحو الآخر & \\
\hline
\end{tabular}


تابع جدول (11)

معاملات الارتباط بين اضطراب الثخصية الاعتمادية والمخططات اللاتكفية المعرفية

\begin{tabular}{|c|c|c|c|c|c|c|}
\hline.$V \cdot 0^{* * *}$ & .940"* & $.110^{* * *}$ &.$\vee \vee q^{* * *}$ & $. \wedge \leq 7^{* * *}$ & الكبت العاطقي & \multirow{3}{*}{ الانفعالي } \\
\hline $.911^{* *}$ & $\cdot v \cdot q^{* * *}$ & $.7 \vee \Lambda^{* * *}$ & $. \wedge 0 . * *$ & $. V \leq \leqslant * *$ & المعايير الصارمة/ النفاق & \\
\hline$\cdot v \cdot r^{* * *}$ &.$\wedge \vee v^{* *}$ &.$V r V^{* * *}$ &.$\vee \diamond q^{* *}$ & $. v r . * *$ & الانفعالي/الحذر & \\
\hline$\cdot, . \Delta r$ & $\cdot, \cdot \leq 4$ & $\cdot, \cdot \leq \leqslant$ & $\cdot, \cdot \leq 4$ & $\cdot, \cdots 9$ & الاستخفاف/ هوس العظمة & \multirow{3}{*}{ ضعف القيود الحدود } \\
\hline$\cdot, 1 \cdot r$ & $\cdot, I r v$ & $\cdot, \cdot \wedge 9$ & 4 & $\cdot, 111$ & العجز عن ضبط الذات & \\
\hline$\cdot, \cdot r \varepsilon$ & $\cdot, .09$ & דצ', & $\cdot, \cdot r \Lambda$ & $\cdot, .11$ & ضعف القيود أو الحدود & \\
\hline
\end{tabular}

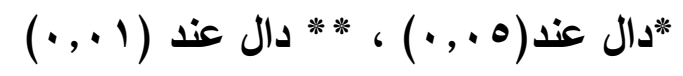

يتضح من جدول (Y) (Y) وجود علاقة ارتباطية موجبة دالة احصائيا بين اضطراب الثخصية الاعتمادية

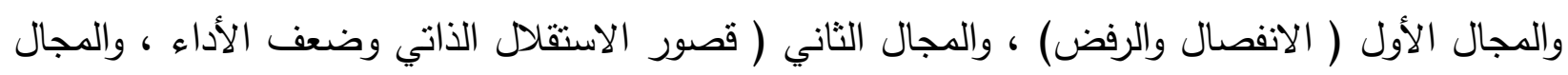

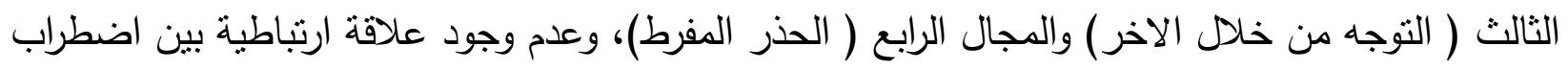
الثخصية الاعتمادية والمجال الأخير (ضعف الحدود أو القيود) •

أثنارت العديد من الدراسات السابقة إلي العلاقة بين المخططات المعرفية اللاتكيفية المبكرة والاضطرابات النفسية والعقلية واضطرابات الثخصية منل اضطراب الثخصية الحديّة كما في دراسة:

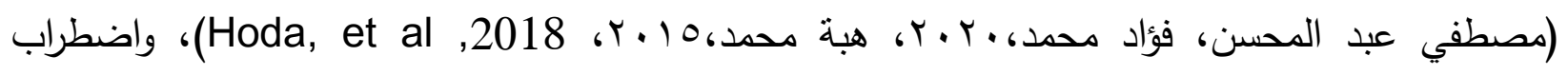

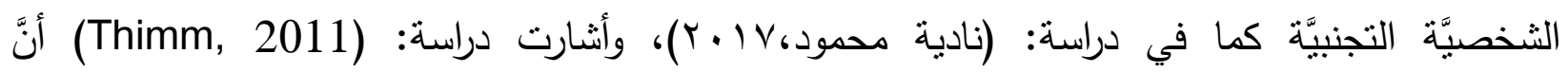

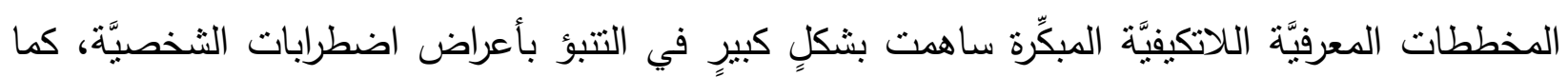

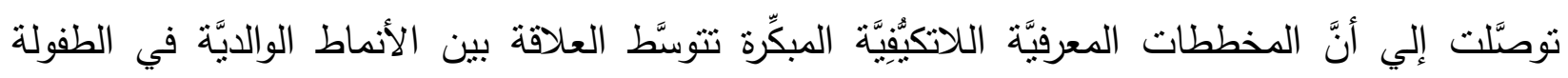

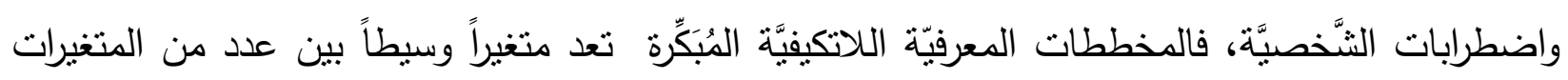

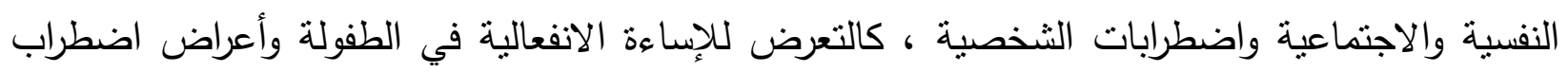


وفسرت الباحثة وجود ارتباط موجب دال احصائيًا بين كل المخططات المعرفية اللاتكيفية وكل أبعاد

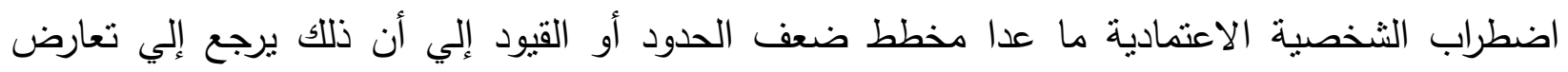
صفات هذا المخطط من هوس العظمة وعدم احترام القيود والحدود وعدم القدرة علي ضبط الذات وتهذيبها مع صفات شخصية ذوى اضطراب الثخصية الاعتمادية، لأن الثخص في هذا المجال تتنابه الأنانية والعظمة ويشعر بالتقوق علي أقرانه ساعيًا إلي تحقيق مصالحه الثخصية دون اعتبار للقيم، فهي شخصية تري نفسها فوق الجميع وتسعى لإخضاع الآخرين لتلبية رغباتهم وهذا يتتاقض مع سمات الثخصية

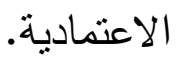

فمن المخططات الفرعية التابعة لمجال قصور الاستقلال الذاتي وضعف الأداء مخطط الاعتمادية (الاتكالية) ويعني عدم قدرة الفرد علي تحمل مسئولياته اليومية أو اتخاذ قراراته وعجزه عن التعامل مع التعلينه منطلباته دون مساعدة الآخرين، ومخطط الفشل في تحقيق الهدف حيث يسيطر علي الفرد الثعور بالفشل إذا بدأ في أي عمل بمفرده وكل ما يتضح في هذا المخطط من صفات متطابقة تمامً مع اضطراب الثخصية الاعتمادية، وأيضًا في مجال الانفصال والرفض يتضح عدم اشباع حاجات الفرد للتعلق الآمن بالآخرين

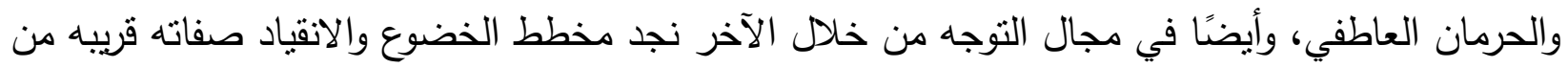
اضطراب الثخصية الاعتمادية.

ويمكن تفسير ذلك الفرض في ضوء أساس نشأة المخططات فهي تظهر نتيجة خبرات الطفولة

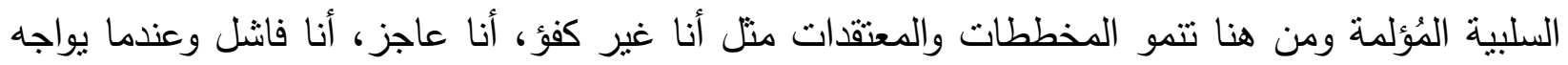
الفرد في مرحلة الرشد أو المراهقة مواقف صادمة مماتلة لما كان يحدث في طفولته هنا تتشط المخططات

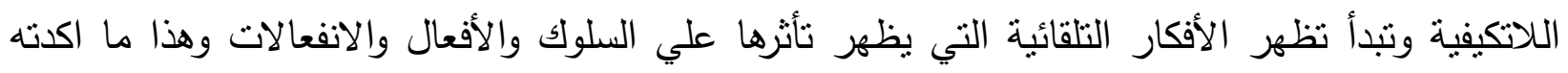
نادية محمود غنيم عبد العزيز (Y.lV) بأن تفاعل التعرض للخبرات السلبية في الطفولة مع المخططات المعرفية اللا تكيفية يزيد من حدة اضطرابات الثخصية .

أظهرت دراسة رندا محمد سيد (·.r.r) وجود علاقة ارتباطية طردية دالة إحصائيا بين الجانب

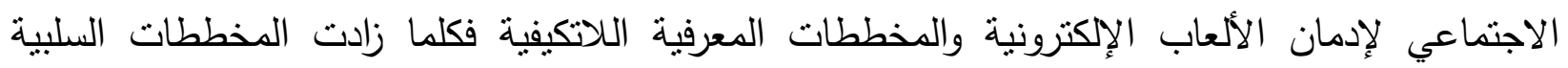
والمعتقدات الخاطئة للي لطالبات الجامعيات كلما ارتفع ادمان الألعاب الالكترونية ، كما توصلت دراسة 


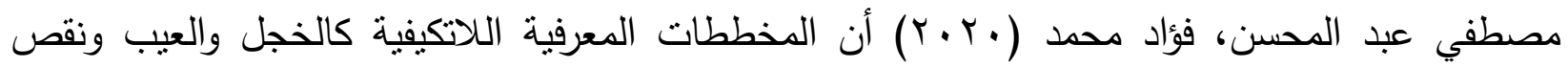
ضبط الذات وعدم الكفاية والدونية تتوسط العلاقة بين أساليب التعلق وأعراض اضطراب الشخصية التجنبية،

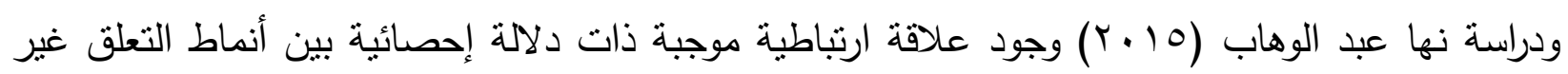

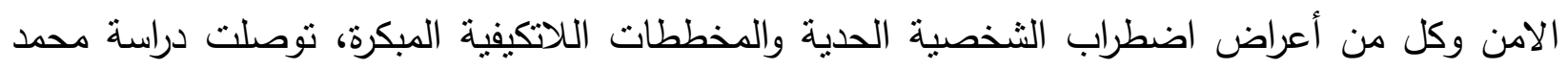

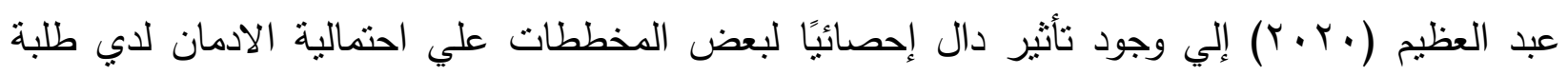
الجامعة كما يوجد نموذج سببي يفسر العلاقة بين المخططات المعرفية اللاتكيفية المبكرة علي احتمالية

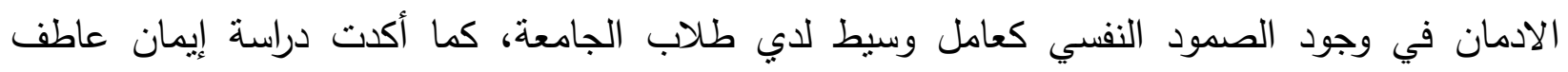

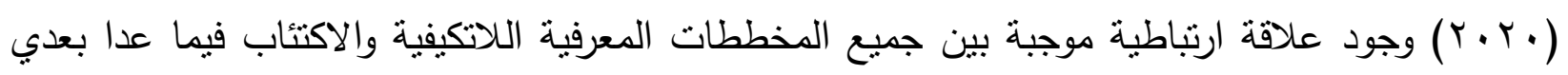
التعلق ، هوس العظمة/ الاستحقاق.

ويمكن التفسير أيضًا في ضوء أن المخططات المعرفية اللاتكيفية نكون مصاحبة بنوقعات وأفكار واتجاهات سلبية نحو الفرد والمحيطين به والعالم من حوله والمستقبل حيث أن وجودها يساعد في تتويه الواقع وبث روح التشاؤم وضعف التقة بالنفس والاعتماد عليها ووساوس بعدم القدرة علي تحمل المسئولية مما يوفر بيئة خصبة لظهور الأعراض الاعتمادية. نتائج الفرض الثاني:

ينص الفرض الثاني علي أنه " توجد فروق ذات دلالة إحصائية بين متوسطات درجات ( الذكور والإناث علي مقياس اضطراب الثخصية الاعتمادية. للتحقق من صحة الفرض قامت الباحثة بنطبيق مقياس

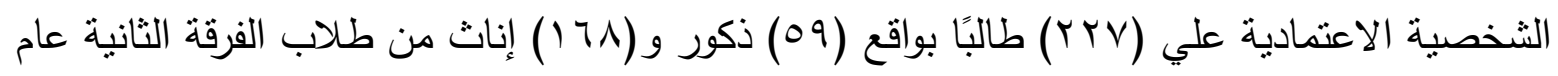

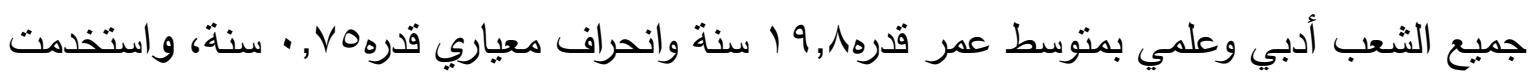

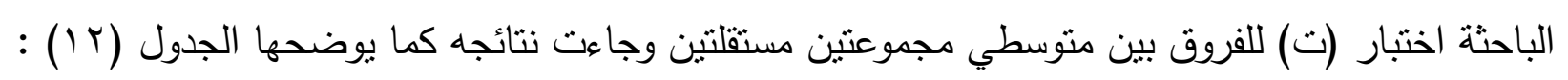


جدول (T)

اختبار "ت" ومستوى دلالتها للفروق بين متوسطي درجات الذكور والاناث علي مقياس الثخصية الاعتمادية

\begin{tabular}{|c|c|c|c|c|c|}
\hline ت ودلالاتها & الانحراف & المتوسط & العدد & الاجتماعي النوع & البعد \\
\hline.$r \wedge \varepsilon$ & Y.A०० & 17.71 & 09 & الأكور & الاعتماد الزائد علي \\
\hline غير دالة & r.AVr & 17.89 & 171 & الاناث & الآخرين \\
\hline .471 & r.rov & 1 r.1. & 09 & الأكور & صعوية الاختلاف مع \\
\hline غير دالة & r.ra. & Ir.rT & 171 & الاناث & الآخرين \\
\hline
\end{tabular}

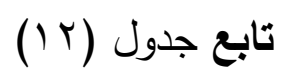

اختبار "ت" ومستوى دلالتها للفروق بين متوسطي درجات الذكور والاناث علي مقياس الثخصية الاعتمادية

\begin{tabular}{|c|c|c|c|c|c|}
\hline$r . v \cdot r$ & $r . v \cdot r$ & $11 . .0$ & 09 & الأكور & \multirow{2}{*}{ ضعف الثقة بالنفس } \\
\hline دالة عند & r.710 & 19.97 & 171 & الاناث & \\
\hline$\Rightarrow v \leq \Lambda$ & r...rY & 17.1. & 09 & الأكور & \multirow{2}{*}{ الخوف من الابتعاد } \\
\hline غير دالة & 9.191 & ه.r. & 171 & الاناث & \\
\hline r..q. & $7.7 \leqslant 1$ & Tr.qr & 09 & الأكور & \multirow[t]{2}{*}{ الاعتمادية ككل } \\
\hline دالة عند & V.AIA & TO.r. & 171 & الاناث & \\
\hline
\end{tabular}

يتضح من جدول (1) وجود فروق دالة احصائًا عند مستوي دلالة (1 (.,.) بين الذكور والإناث لصالح الإناث في بعد ضعف الثقة بالنفس، كما وجدت فروق دالة إحصائًًا عند مستوبي دلالة (0., ••) لصالح الإناث أيضًا في الدرجة الكلية لمقياس الثخصية الاعتمادية، لا توجد فروق بين الجنسين في بعض أبعاد 
مقياس اضطراب الثخصية الاعتمادية وهي( الاعتماد الزائد علي الآخرين، صعوبة الاختلاف مع الآخرين، الخوف من الابتعاد عن الآخرين).

يمكن تفسير النتائج في ضوء نظرة المجتمع الذكورية حيث تنظر للأنثى بأنها دومًا في المرنبة الثانية للذكر وأنها ضعيفة وقليلة الحيلة ولا تستطيع تحمل المسئولية، فنجد أن معظم الناس يكرروا الآية

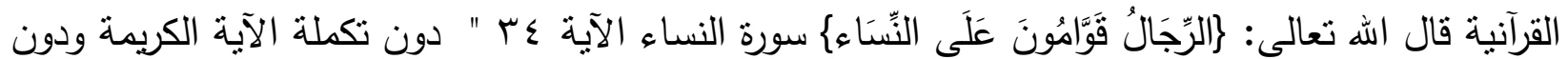
فهم معناها، فمن المعروف ان لكل نوع سواء ذكر أو أنثي له أدوار اجتماعية ومسئوليات حسب الآبه تكوينه الجسمي والنفسي و قيامهم بالأدوار والمسئوليات المطلوبة منهم يكون الفرق في طريقة الثكر والتعزيز والثناء، فمثلا عندما يقوم الذكر بشيء ما سوي وصحيح نجد الأسرة والمجتمع تُقابله بحفاوة وتقدير وتعزيز

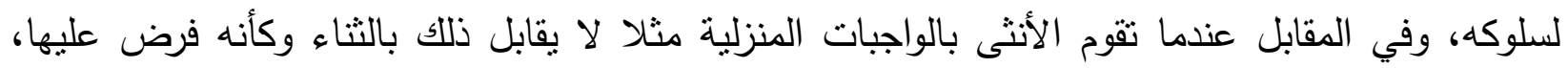
فإحساسها الدائم بالنقص والدونية وعدم الثقة بالنفس يجعلها تبحث عن علاقات حميمة دع الاخرين بشكل مستمر وتخاف من الانفصال عنهم.

وهذه النتيجة تتفق مع دراسة محمد عاطف، ومحمد أبو الخير (.... أني توصلت إلي أن الإناث أكثر اعتمادية من الذكور، وأيضًا دراسة (2001) Pavilids, McCauley أثنارت إلي ان الاعتمادية نزداد

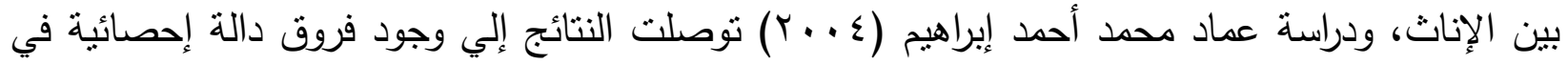
بعد الافتقار إلي النضج والهروب من تحمل المسؤولية لدي الإناث دون الذكور، ودراسة دلال كاظم ابراهيم

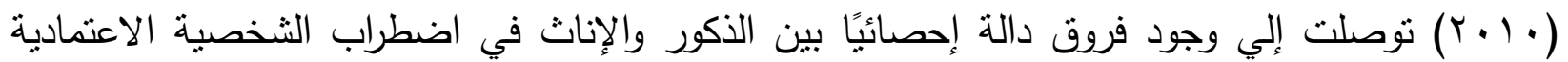

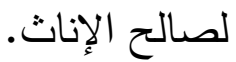

كما توصلت دراسة Bogaerts, et al, (2020) أن الفروق في اضطراب الثخصية الاعتمادية لصالح الإناث وفسرت هذه الفروق نتيجة التركيب الفسيولوجي والنفسي الذي يميز الذكور عن الإناث في Sayyeda القوة العضلية وإعطائهم مهام معقدة ومهمة مما يمنحهم الثقة بالنفس، كما فسرت نتائج دراسة

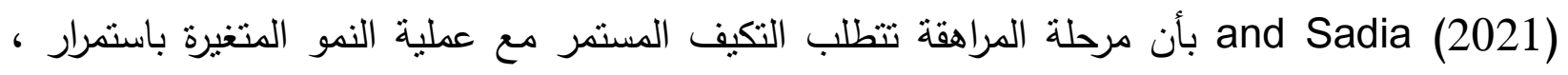
وخلال هذه الفترة يواجه المراهقون العديد من الضغوط والتحديات ، منل تكوين الهوية ، والتغيرات البيولوجية

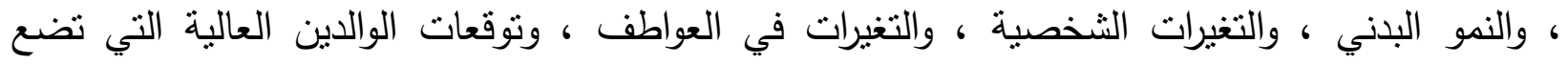
المراهقين في تحدي وصراع ومشاكل نفسية. وتعد ضعف الثقة بالنفس من أبرز مشكلات الصحة النفسية 
الني يعاني منها المراهقون علي وجه عام والإناث علي وجه خاص لأن الأنثى أكثر حساسية وتأثرًا بالضغوط من الذكور

كما يمكن التفسير في ضوء أن الفروق بين الذكور والإناث مرتبطة ارتباطا وثيقا بالتتشئة الاجتماعية

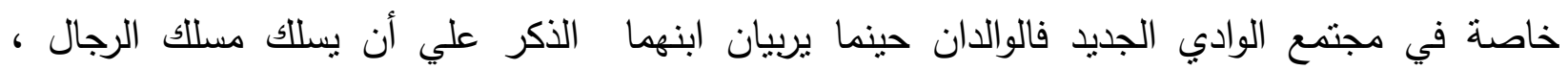

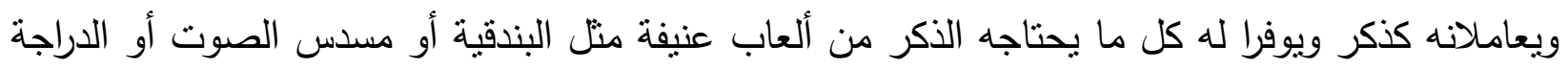

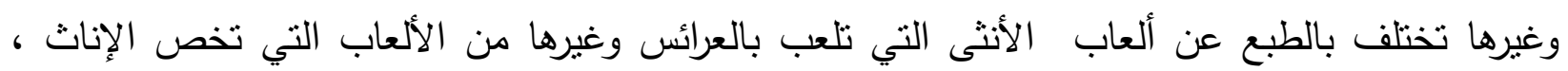

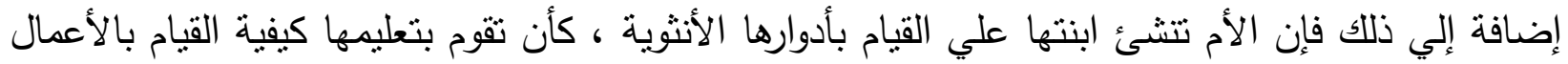

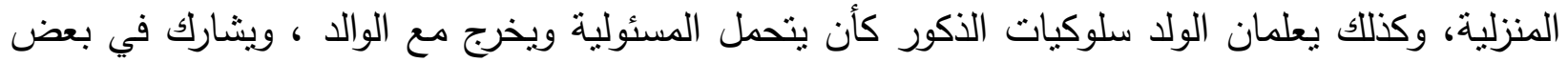

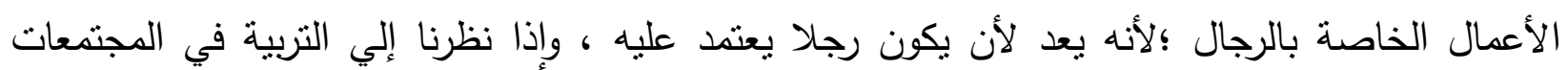

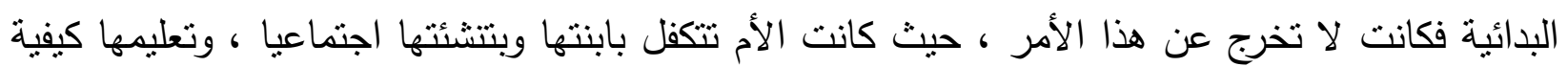

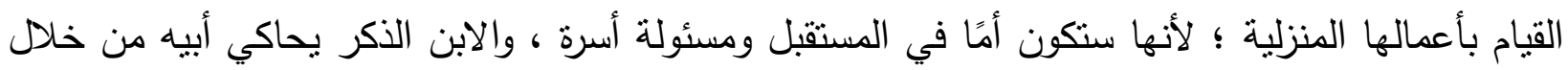
مصاحبته وملاحظة سلوكياته وبالتالي يثب أكثر ثنقة بالنفس. 


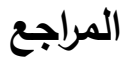

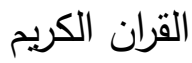

إيمان عاطف محمد (·r · r ). المخططات المعرفية اللاتكيفية وعلاقتها بالاكتئاب لدي طلاب الجامعة. الدجلة العربية للآداب والدراسات الانسانية، 0 1، الو-؟ 9.

إيمان عطية حسين (Y V r). الأعراض الاكتئابية وعلاقتها بالأكسيثيميا والمخططات المعرفية اللاتكيفيَّة

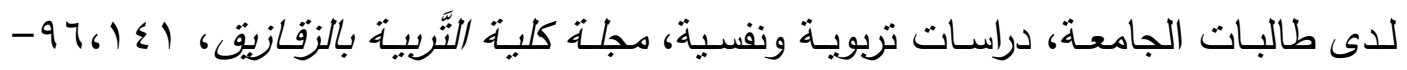

\section{. rYq}

جونسـون، شيري، دفايسون، جيرالد، نيالي، جون، كارنج، آن م (10 ب ب)، علم النفس المرضسي ترجمـة

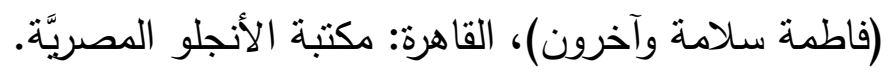

دلال كاظم إبراهيم طـاهر (· ( • ( ). اضطراب الثخصية الاعتماديَّة وعلاقته بـانغلاق الذات والتفكير

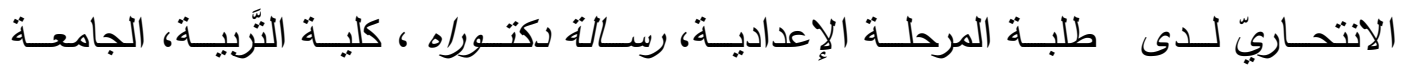

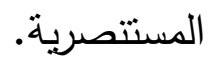

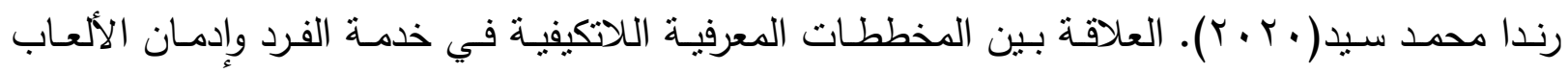

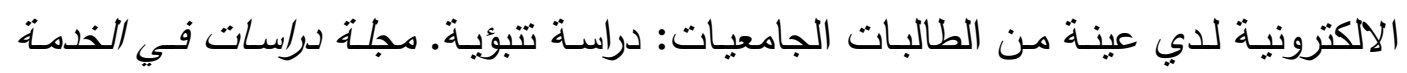

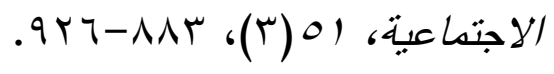

سلوى فهاد حماد المري (10 • ب). الاعتمادية ونقد الأَّات السلبيّ كمتغيرات وسيطة في العلاقة بين الكمالية

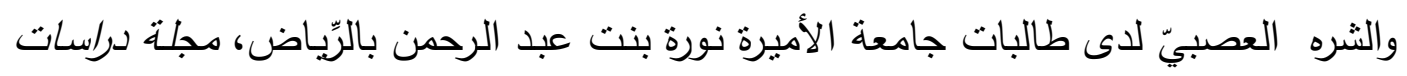

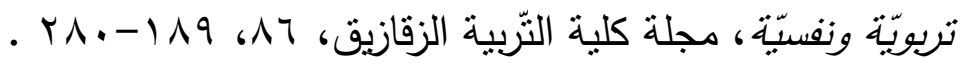

صفوت فرج (1991 (1). التحليل العاملي في العلوم السلوكبة. مكتبة الأنجلو المصرية. 


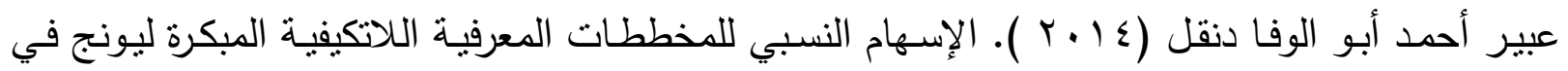
التتبؤ بالصحة النفسية وبعض الحالات الانفعالية لدي طلاب الجامعة. مجلة كلية التتبية،

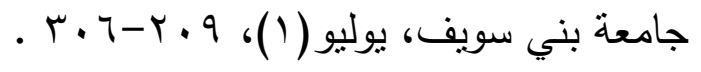

عماد محمد أحمد إبراهيم مخيمر (ع . . ب) • قلق الانفصال لدي الوالدين وعلاقته باعتمادية الأبناء في مرحلة

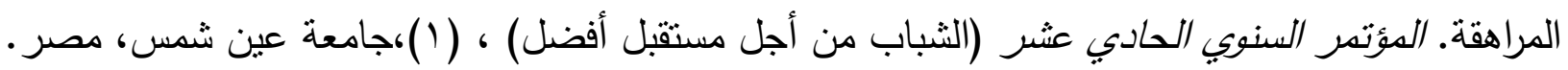

محمد السيد عبد الرحمن، محمد أحمد إبراهيم سعفان (؟ ( • ب). مقياس الدخططات الدعرفية اللاتكيفية.

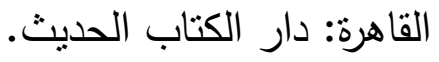

محمد عاطف رشاد زعتر ، محمد محمد سعيد أبو الخير (.... · • اضطراب الثخصية الاعتمادية وعلاقته بـإدرالك الضـوابط الو الديـة والاتجـاه نحو تعـاطي المخدرات لدي طـلاب المرحلـة الثانويـة.

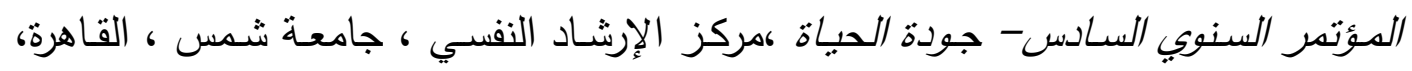

$$
.0 \leq 0-710
$$

محمد عبد العظيم محمد (·r · ·). النموذج البنائي بين احتمالية الادمان والمخططات المعرفية اللاتكيفية

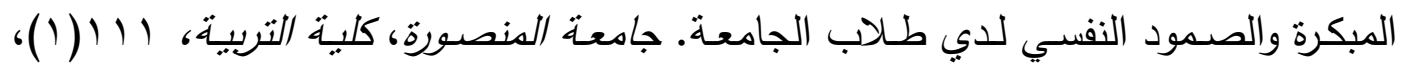
$. \varepsilon \leqslant V-r V \leqslant$

مصطفى عبد الدحسن الحديبي، فؤاد محمد الدواش (•r.r). النموذج السببي للعلاقة بين الدخططات

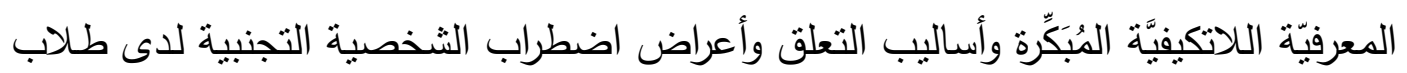

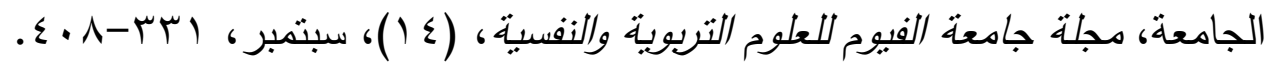

نادية محمود غنيم عبد العزيز (Y V • r). المخططات المعرفية اللاتكيفية كمتغير وسيط بين الخبرات النفسية

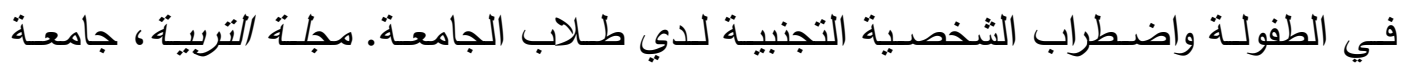

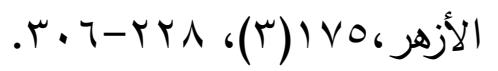




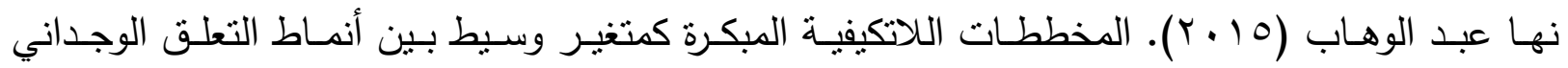

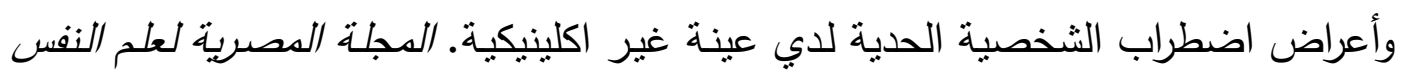

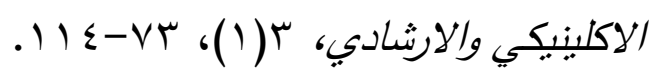

هبة محمد علي حسن (10 • ( ). المخططات المعرفية اللاتوافقية المنبئة باضطراب الثخصية الحديّة لاى

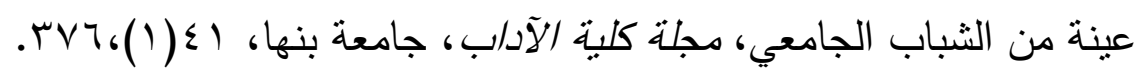




\section{References :}

American Psychiatric Association (2000). Diagnostic and Statistical manual of mental disorders. Text revision (4th ed. Text revision). Washington; DC: American Psychiatric Association, 685-725.

American Psychiatric Association (2013). Diagnostic and statistical manual of mental disorders (5th ed.). Washington, DC: Author. American Psychiatric Association .

Beck, A.\& Freeman, A.(1990). Cognitive therapy of personality disorder. New York, Guilford Press.

Bogaerts, A., Claes, L., Bastiaens, T., \& Luyckx, K. (2020). Personality disorder symptomatology in Belgian emerging adults: Associations with identity processes and statuses. European Journal of Developmental Psychology, $1-21$.

Bornstein (1992). The dependent personality : developmental, social, and clinical perspectives . Psychological bulletin , 112( 1), 3-23.

Faith, C. (2009) ."Dependent Personality Disorder: A Review of Etiology and Treatment," Graduate Journal of Counseling Psychology, 1(2).

Fritz, R., Jill, L., Frenk, P., Arnoud, A., Marcus, H. (2012). Early maladaptive schemas in depressed patients: Stability and relation with depressive symptoms over the course of treatment. Journal of Affective Disorders, 136 , 581-590. 
Hoda B. , David.W , Naysun S. \& Michael G. (2018). Schema modes and dissociation in borderline personality disorder/traits in adolescents or young adults. Psychiatry Research,261,1-6.

Liesbeth, D.(2017). The effectiveness of schema focused drama therapy for cluster C personality disorders: an exploratory study. The Arts in Psychotherapy,61,66-76.

Michal, L., Annamaria, G., Tillmann, H. (2021). Psychiatry and Sexual Medicine A Comprehensive Guide for Clinical Practitioners. Springer Nature Switzerland AG,306-307.

Pilkington, P., Younan, R., \& Bishop, A. (2020). Early Maladaptive Schemas, Suicidal Ideation, and Self-Harm: A Meta-analytic Review. Journal of Affective Disorders Reports, 100051. doi:10.1016/j.jadr.2020.100051.

Sayyeda, T., Sadia, S.(2021). Family cohesion and depression in adolescents: A mediating role of self-confidence. Journal of the Pakistan Medical Association, 1-10.

Theiler, S.(2005). The efficacy of early childhood memories as indicators of current maladaptive schemas and psychological health. School of Social and Behavioral Sciences, Swinburne University of Technology.

Thimm, J. (2010). Mediation of early maladaptive schemas between perceptions of parental rearing style and personality disorder symptoms. Journal of Behavior Therapy and Experimental Psychiatry,41,52-59. 
Thimm, J. (2011). Incremental validity of maladaptive schemas over five-factor model facets in the prediction of personality disorder symptoms. Personality and Individual Differences,50, 777-782.

Wang E.A, Halvorsen, M. ,Eisemann, M., Waterloo, K. (2010). Stability of dysfunctional attitudes and early maladaptive schemas. Study of clinically depressed subjects,41,389-396.

Young, J. (1999). Cognitive therapy for personality disorder: A schema _ Focused approach ( third Edition). Professional Resources Pess, Sarasota, Florida.

Young, J.\& Brown, G (2003). Young Schema questionnaire . In J.E . Young (Ed) Cognitive therapy for personality disorder: A schema _ Focused approach ( third Edition). Professional Resources Pess, Sarasota, Florida.

Young,J., Beck,B., Weinberger(1993). Depression. In D.H. Barlow(Ed), Clinical Handbook Psychological Disorders, New York, Guilford Press, 240-277.

Young, Janet S. Klosko et Marjorie E. Weishaar (2005). La Therapie des Schemas. Bruxelles Approche cognitive des troubles de la personnalité. The Guilford Press, Edition de boeek. 